\title{
The influence of soil properties and nutrients on conifer forest growth in Sweden, and the first steps in developing a nutrient availability metric
}

\author{
Kevin Van Sundert ${ }^{1}$, Joanna A. Horemans ${ }^{1}$, Johan Stendahl ${ }^{2}$, and Sara Vicca ${ }^{1}$ \\ ${ }^{1}$ Centre of Excellence PLECO (Plants and Ecosystems), Biology Department, \\ University of Antwerp, Wilrijk, 2610, Belgium \\ ${ }^{2}$ Department of Soil and Environment, Swedish University of Agricultural Sciences, \\ P.O. Box 7014, Uppsala, 75007, Sweden
}

Correspondence: Kevin Van Sundert (kevin.vansundert@uantwerpen.be)

Received: 30 August 2017 - Discussion started: 2 November 2017

Revised: 10 May 2018 - Accepted: 28 May 2018 - Published: 13 June 2018

\begin{abstract}
The availability of nutrients is one of the factors that regulate terrestrial carbon cycling and modify ecosystem responses to environmental changes. Nonetheless, nutrient availability is often overlooked in climate-carbon cycle studies because it depends on the interplay of various soil factors that would ideally be comprised into metrics applicable at large spatial scales. Such metrics do not currently exist. Here, we use a Swedish forest inventory database that contains soil data and tree growth data for $>2500$ forests across Sweden to (i) test which combination of soil factors best explains variation in tree growth, (ii) evaluate an existing metric of constraints on nutrient availability, and (iii) adjust this metric for boreal forest data. With (iii), we thus aimed to provide an adjustable nutrient metric, applicable for Sweden and with potential for elaboration to other regions. While taking into account confounding factors such as climate, $\mathrm{N}$ deposition, and soil oxygen availability, our analyses revealed that the soil organic carbon concentration (SOC) and the ratio of soil carbon to nitrogen $(\mathrm{C}: \mathrm{N})$ were the most important factors explaining variation in "normalized" (climateindependent) productivity (mean annual volume increment $-\mathrm{m}^{3} \mathrm{ha}^{-1} \mathrm{yr}^{-1}$ ) across Sweden. Normalized forest productivity was significantly negatively related to the soil $\mathrm{C}: \mathrm{N}$ ratio $\left(R^{2}=0.02-0.13\right)$, while SOC exhibited an empirical optimum $\left(R^{2}=0.05-0.15\right)$. For the metric, we started from a (yet unvalidated) metric for constraints on nutrient availability that was previously developed by the International Institute for Applied Systems Analysis (IIASA - Laxenburg, Austria) for evaluating potential productivity of arable land. This
\end{abstract}

IIASA metric requires information on soil properties that are indicative of nutrient availability (SOC, soil texture, total exchangeable bases - TEB, and $\mathrm{pH}$ ) and is based on theoretical considerations that are also generally valid for nonagricultural ecosystems. However, the IIASA metric was unrelated to normalized forest productivity across Sweden $\left(R^{2}=0.00\right.$ 0.01 ) because the soil factors under consideration were not optimally implemented according to the Swedish data, and because the soil $\mathrm{C}: \mathrm{N}$ ratio was not included. Using two methods (each one based on a different way of normalizing productivity for climate), we adjusted this metric by incorporating soil $\mathrm{C}: \mathrm{N}$ and modifying the relationship between SOC and nutrient availability in view of the observed relationships across our database. In contrast to the IIASA metric, the adjusted metrics explained some variation in normalized productivity in the database $\left(R^{2}=0.03-0.21\right.$; depending on the applied method). A test for five manually selected local fertility gradients in our database revealed a significant and stronger relationship between the adjusted metrics and productivity for each of the gradients $\left(R^{2}=0.09-0.38\right)$. This study thus shows for the first time how nutrient availability metrics can be evaluated and adjusted for a particular ecosystem type, using a large-scale database. 


\section{Introduction}

Nutrients determine structure and functioning at all levels of biological organization. The availability of mineral elements influences plant growth (von Liebig, 1840), patterns of biodiversity (Fraser et al., 2015), and ecosystem processes (e.g., Janssens et al., 2010; Vicca et al., 2012; FernándezMartínez et al., 2014). Moreover, nutrient availability can modify ecosystem responses to global atmospheric and climatic changes, such as nitrogen $(\mathrm{N})$ deposition (Nohrstedt, 2001; Hyvönen et al., 2008; Vadeboncoeur, 2010), increasing $\mathrm{CO}_{2}$ levels (Norby et al., 2010; Terrer et al., 2016), warming (Dieleman et al., 2012), and drought (Friedrich et al., 2012). Given the crucial role of nutrients in terrestrial carbon cycling and in shaping the magnitude and direction of its feedbacks to climate change, nutrient availability should be taken into account in global analyses and in Earth system models (Goll et al., 2012; Thomas et al., 2015; Wieder et al., 2015). This is, however, not yet common practice because we often lack the soil data and metrics needed to accurately account for nutrient availability.

Comparing nutrient availability among terrestrial ecosystems is difficult for two reasons: comprehensive and harmonized data on soil properties and nutrients are not usually available from experimental and observational sites, and no standardized quantitative metric exists to compare the nutrient statuses of terrestrial ecosystems at the global scale, or even at a national scale (e.g., for Sweden, which is considered in this study). In the absence of a standardized nutrient availability metric, studies comparing nutrient availability across sites commonly use soil-fertility-related approximations such as the height of 100-year-old trees (which, however, also depends on other factors such as soil depth and hydrology - Hägglund and Lundmark, 1977) or manually classify sites as low, medium, and high nutrient availability based on existing site information (Vicca et al., 2012; FernándezMartínez et al., 2014). The absence of a more nuanced expression impedes elucidating the role of nutrient availability in ecosystem processes and functioning (Cleveland et al., 2011) and how these respond to global change, and it precludes investigating nonlinear effects of nutrient availability.

Although various proxies exist to estimate soil $\mathrm{N}$ and phosphorus (P) availability at the local scale (e.g., "snapshots" of extractable pools), no perfect method exists to quantify $\mathrm{N}$ and $\mathrm{P}$ availability in a comparable way across ecosystems (Binkley and Hart, 1989; Holford, 1997; Neyroud and Lischer, 2003). This limits the potential for inter-site comparisons based on these data alone (Cleveland et al., 2011). Soil properties like soil texture, soil organic matter (SOM) quantity and quality, and $\mathrm{pH}$, however, are more indicative of the general nutrient status because together with environmental factors (temperature and moisture - Binkley and Hart, 1989), they control (1) the total amount of nutrients in soil solution, (2) ion exchange sites, and (3) unavailable pools of soil nutrients, as well as fluxes among these three (Roy et al.,
2006). For instance, a high clay fraction corresponds to a high cation exchange capacity (CEC), i.e., the soil's potential to retain positively charged, exchangeable ions such as $\mathrm{NH}_{4}^{+}, \mathrm{K}^{+}, \mathrm{Ca}^{2+}$, and $\mathrm{Mg}^{2+}$ (Chapman, 1982; Chapin et al., 2002), while SOM has a positive influence on nutrient availability by acting as a nutrient reserve (Grand and Lavkulich, 2015) and provides cation as well as anion exchange sites (IIASA and FAO, 2012). Finally, soil pH strongly influences availability of $\mathrm{P}$ and base cations $\left(\mathrm{K}^{+}, \mathrm{Ca}^{2+}\right.$, and $\left.\mathrm{Mg}^{2+}\right)$. At low $\mathrm{pH}, \mathrm{P}$ is bound to $\mathrm{Fe}$ and $\mathrm{Al}$ oxides, while at high $\mathrm{pH}, \mathrm{P}$ is typically unavailable because of complex formation with $\mathrm{Ca}$. $\mathrm{P}$ availability is thus maximal at intermediate $\mathrm{pH}$ (Chapin et al., 2002; Bol et al., 2016), while enhanced leaching of base cations occurs in acidic soils, thus reducing TEB (i.e., the cation equivalent of summed $\mathrm{K}, \mathrm{Ca}, \mathrm{Mg}$, and $\mathrm{Na}-$ IIASA and FAO, 2012). Hence, unlike temperature or precipitation, nutrient availability cannot be assessed by measuring one single parameter. It is determined by the interplay of various nutrients and soil properties. A nutrient availability metric should thus combine critical soil properties and nutrients, while considering important nonlinearities. To be widely applicable, such a metric is preferably constructed only of easyto-obtain variables.

Only a few exploratory attempts to find an expression for nutrient availability at the global scale have been made. The most recent one was developed by IIASA and FAO, who provide a simple index in their Global Agro-ecological Zones report of 2012 (IIASA and FAO, 2012). It is a worldwideapplicable metric for constraints on nutrient availability, principally meant for agricultural purposes. This metric represents, for a particular crop species, the percentage of the maximum attainable productivity that could be reached given constraints imposed by environmental characteristics such as climate, rooting conditions, and soil oxygen availability but absent nutrient limitation:

actual productivity
$=\frac{\text { metric score [\%] - attainable productivity }}{100}$.

The species-specific score of the metric depends on four measurable soil variables, related to soil fertility: SOC (\%), soil texture, TEB $\left(\mathrm{cmol}_{+} \mathrm{kg}^{-1} \mathrm{dw}\right)$, and $\mathrm{pH}$ measured in water $\left(\mathrm{pH}_{\mathrm{w}}\right)$. The metric score combines the scores of each of these four attributes (provided in a lookup table), but giving more weight to the attribute with the lowest score. Together with the nonlinear relationships (e.g., for $\mathrm{pH}$ and SOC - see Sect. 2), this increases the realism of the metric (see Liebig's law of the minimum (von Liebig, 1840); e.g., at optimal $\mathrm{pH}$, the limiting effect of low SOC on plant growth will be stronger than in soils with very low or high $\mathrm{pH}$ in which plant growth becomes more likely to be $\mathrm{P}$ limited).

To the best of our knowledge, the accuracy of the IIASA metric has not yet been tested against data from natural ecosystems, and it is not known to what extent the metric 
- aimed at describing constraints on nutrient availability can describe variation in nutrient availability of nonagricultural soils. Evaluation of the IIASA metric, and further development of a widely applicable metric of nutrient availability, requires datasets that combine the necessary information on soil properties and nutrients with data on plant productivity, while also covering a substantial variation in nutrient availability. Such a unique dataset - which comprises $>2500$ conifer forest plots and thus provides sufficient statistical power for an evaluation of the metric - is provided by the Swedish forest inventory service. Moreover, it contains additional variables of interest related to $\mathrm{N}$ availability, such as total soil $\mathrm{N}$ stock and concentration, and especially the soil $\mathrm{C}: \mathrm{N}$ ratio, which we expected to be an important factor in explaining variation in nutrient availability. This large dataset also allows the evaluation of our country-scale findings against local gradients in nutrient availability that avoid confounding effects of covarying factors such as climate and $\mathrm{N}$ deposition.

Specifically, we used the Swedish dataset to address the following questions:

Question 1: Which single soil variables can explain variation in normalized (i.e., climate-independent) productivity across Sweden? Which combination of soil factors best explains variation in normalized productivity?

Question 2: Can the IIASA metric of constraints on nutrient availability explain variation in normalized productivity? Are the soil variables already included in the metric (SOC, soil texture, TEB, and $\mathrm{pH}_{\mathrm{w}}$ ) accurately implemented?

Question 3: Can the IIASA metric be adjusted to characterize nutrient availability in Swedish forests?

\section{Methods}

\subsection{The Swedish forest and soil inventories (national database)}

We combined a Swedish forest soil (Olsson, 1999; Lundin, 2011) and inventory database for the period 2003-2012 (Lundin, 2011) with a database for soil texture and climate information across Sweden. Precipitation data were extracted from the European Commission Joint Research Centre Monitoring Agricultural Resources dataset (EC-JRCMARS, based on ECMWF model outputs and a reanalysis of ERA-Interim; see http://spirits.jrc.ec.europa.eu/; last access: 7 June 2018) based on the geographic location of each site. The dataset's spatial resolution is $0.25^{\circ}$ and averages were calculated for the period 1989-2012. The resulting data collection thus incorporated information on location, climate, soil, and vegetation for about 2500 forested plots $(n=1099$ for spruce, $n=1422$ for pine) spread over Sweden (Table 1).
Many of the (mostly managed) forest plots were not monocultures, but contained both Norway spruce (Picea abies (L.) H. Karst.) and Scots (or lodgepole) pine (Pinus sylvestris L. or Pinus contorta Douglas) trees, as well as other species. In order to contrast spruce and pine forests, we classified forests with $\geq 50 \%$ basal area of spruce (pine) trees as spruce (pine). To quantify the influence of climate on productivity across Sweden (Question 1), we first determined the annual growing season temperature sum (TSUM) following a recently reparameterized version of the equation given in Odin et al. (1983), available on https://www.skogskunskap.se/; last access: 7 June 2018.

$$
\begin{aligned}
& \text { TSUM }\left({ }^{\circ} \mathrm{C} \text { days }\right) \\
& \quad=4203.212488-40.21083 \cdot \text { latitude }\left({ }^{\circ} \mathrm{N}\right) \\
& -2.564434 \cdot \text { elevation }(\mathrm{m}) \\
& +0.030492 \cdot \text { latitude }\left({ }^{\circ} \mathrm{N}\right) \cdot \text { elevation }(\mathrm{m}) \\
& -0.117532 \cdot \text { latitude }^{2}\left({ }^{\circ} \mathrm{N}\right) \\
& +0.00188 \cdot \text { elevation }^{2}(\mathrm{~m}) \\
& -0.000000556 \cdot \text { latitude }^{2}\left({ }^{\circ} \mathrm{N}\right) \cdot \text { elevation }^{2}(\mathrm{~m})
\end{aligned}
$$

In order to facilitate comparisons among sites and to allow the calculation of the nutrient availability metric, we converted the soil measurements ( $\mathrm{SOC}$, soil texture, TEB, $\mathrm{pH}_{\mathrm{w}}$, $\mathrm{pH}_{\mathrm{KCl}}$, total nitrogen concentration (TN), and soil $\mathrm{C}: \mathrm{N}$ ratio) taken per horizon to values representative of the upper $10 \mathrm{~cm}$ (i.e., the $0-10 \mathrm{~cm}$ layer) and the upper $20 \mathrm{~cm}$ (i.e., the $0-20 \mathrm{~cm}$ layer) of the soil, including the organic layer. To this end, we first calculated bulk densities (BDs) as

$$
\begin{aligned}
& \mathrm{BD}_{\text {organic horizon }}\left(\mathrm{kg} \mathrm{m}^{-3}\right) \\
& \quad=\frac{\text { organic layer stock }\left(\mathrm{kg} \mathrm{m}^{-2}\right)}{\text { organic layer depth }(\mathrm{m})}
\end{aligned}
$$

for the organic horizons and

$$
\begin{aligned}
& \mathrm{BD}_{\text {mineral horizon }}\left(\mathrm{kg} \mathrm{m}^{-3}\right)=1546.3 \\
& \cdot \exp (-0.3130 \cdot \sqrt{\text { total carbon }(\%)})
\end{aligned}
$$

for the mineral soil (Nilsson and Lundin, 2006).

Conversions of soil data ("variables") per horizon to data per depth interval (layer $x-y \mathrm{~cm}$ ) were then performed as follows (soil mass per $\mathrm{m}^{2}\left(\mathrm{~kg} \mathrm{~m}^{-2}\right)=\mathrm{BD}$ $\left(\mathrm{kg} \mathrm{m}^{-3}\right) \cdot$ thickness horizon or layer $\left.(\mathrm{m})\right)$ :

$$
\begin{array}{r}
\text { Variable }_{x-y \mathrm{~cm}}=\left({\text { soil mass horizon } \left.1 / \text { soil mass }_{x-y \mathrm{~cm}}\right)}_{\cdot \text { variable }_{\text {horizon } 1}}\right. \\
+\left(\text { soil mass }_{\text {horizon } \left.2 / \text { soil mass }_{x-y \mathrm{~cm}}\right)}\right. \\
\cdot \text { variable }_{\text {horizon } 2}+\ldots
\end{array}
$$

The IIASA metric of constraints on nutrient availability, originally meant for use on arable land, incorporates four crop-specific scores (estimated for SOC, soil texture, 
TEB, and $\mathrm{pH}_{\mathrm{w}}$ ) that can be assigned to a soil (IIASA and FAO, 2012). These scores, which can be found in lookup tables (http://webarchive.iiasa.ac.at/Research/LUC/ GAEZv3.0/soil_evaluation.html; last access: 7 June 2018), were derived from crop growth data on different agricultural soils. Given that we consider boreal forests and not crops, we averaged the scores of the different crop species for each of the four soil properties. We thus removed cropspecific requirements, but generally known relationships between the soil variables and plant performance (not only valid for agroecosystems), such as an optimum for $\mathrm{pH}$, remained. In addition, we replaced the lookup-table-derived step functions with continuous empirical formulas to facilitate their calculation as well as their modification (Fig. 1):

SOC Score $[\%]=38.94+(100-38.94)$

$$
\cdot(1-\exp (-1.4192 \cdot \mathrm{SOC}[\%])) \text {, }
$$

Soil texture Score $[\%]=\max (100+0.4911$

$$
\cdot(1-\exp (0.0522 \cdot \operatorname{SAND}[\%])), 35) \text {, }
$$

TEB Score $[\%]=28.05+(100-28.05)$

$$
\begin{gathered}
\cdot\left(1-\exp \left(-0.4508 \cdot \mathrm{TEB}\left[\mathrm{cmol}_{+} \mathrm{kg}^{-1}\right]\right)\right), \\
\mathrm{pH} \text { Score }[\%]=\max \left(-17.228 \cdot\left(\mathrm{pH}_{\mathrm{w}}-4.04\right) \cdot\left(\mathrm{pH}_{\mathrm{w}}-8.84\right), 0\right) \\
=\max \left(-17.228 \cdot\left(\mathrm{pH}_{\mathrm{w}}-6.44\right)^{2}+99.32,0\right) .
\end{gathered}
$$

The total score for nutrient availability, which can be interpreted as the expected actual yield (i.e., aboveground productivity) proportional to the maximum attainable yield (i.e., without nutrient constraints), was then calculated as follows (IIASA and FAO, 2012):

total IIASA score $(\%)=0.5 \cdot$ lowest score

$$
+0.5 \cdot \text { average of other scores. }
$$

\subsection{General approach}

Forest productivity across Sweden depends not only on soil nutrient availability but also on climate, soil wetness, and $\mathrm{N}$ deposition. Before evaluating the metric, we removed the influence of climate on forest productivity ("PRE" in Fig. 2). The influence of soil moisture and $\mathrm{N}$ deposition are considered in further analyses (see Sect. 2.3.1). Normalized productivity was calculated in two alternative ways: (1) as the residuals of the regression model (of PRE; from here on referred to as "method 1"; Figs. 3a and S1a, b, Tables S1 and S2, and Eq. S1) and (2) as the ratio of the original productivity relative to the theoretical maximum productivity (from here on referred to as "method 2"; Figs. 3b and S1b, c). This theoretical maximum productivity, which was extracted from a map provided by Bergh et al. (2005) with ArcGIS (ESRI, 2011), indicates the productivity that could be obtained under non-nutrient-limited conditions and is further referred to as attainable productivity. The second method is thus very similar to the IIASA approach (see Eq. 1), but because an estimate for attainable productivity was only available for spruce, it could only be applied for this species. The two alternative methods for normalizing productivity were used to verify the robustness of the analyses, and because each method has its own advantages and disadvantages. The main disadvantage of method 1 is that not only the direct influence of climate on productivity is removed but also its indirect effect through nutrient availability, so that only effects of regional variation in nutrient availability on productivity remain. Method 2, however, involves an extrapolation based on the results of only a few fertilization experiments and thus comes with high uncertainty on the estimates of attainable productivity.

Regression analysis was then used to elucidate how the different soil variables were related to normalized productivity (Question 1). In addition, normalized productivity was fitted against the IIASA metric to test its performance. The correlation between the residuals of this relationship and each of the four variables of the metric then indicated whether or not the variables were well implemented (Question 2). Finally, the associations found in Question 1 indicated how the metric could be adjusted (Question 3). Two adjusted metrics were then evaluated in the same way as the original IIASA metric in Question 2, and by investigating if they could explain variation in productivity for five local gradients in nutrient availability. An overview of the methodology is presented in Fig. 2.

\subsection{Data analyses}

As explained in the paragraphs above, productivity was normalized using two methods. Method 1 considers the residuals to reflect deviations in productivity imposed by spatial variation in nutrient availability and in the absence of climate effects. However, residuals deviated more strongly from zero towards the warmer south (Fig. 3a), thus causing heteroscedasticity and a potential bias in the further analyses if not properly accounted for. For further analyses, we therefore split the database into three TSUM groups (north, middle, and south; Fig. 3a). For method 2, considering the ratio of actual to attainable productivity, this separation of different regions was not required.

\subsubsection{Identifying potentially confounding factors}

In order to understand the correlation structure of the database, and avoid multicollinearity in the subsequent analyses, we examined correlations among the soil variables (SOC, TN, total $\mathrm{N}$ stock, soil $\mathrm{C}: \mathrm{N}$ ratio, sand fraction, clay fraction, TEB, $\mathrm{pHw}$, and $\left.\mathrm{pH}_{\mathrm{KCl}}\right)$. We performed a principal component analysis (PCA) using the princomp function (package MASS - Venables and Ripley, 2002) in R (R Core Team, 2015) for a visualization and constructed a correlation 



Figure 1. IIASA soil scores for soil organic carbon concentration (SOC), texture, total exchangeable bases (TEB), and pH measured in water $\left(\mathrm{pH}_{\mathrm{W}}\right)$. The curves were drawn based on approximate functions through the points, which were derived from crop-specific scores in a lookup table (http://webarchive.iiasa.ac.at/Research/LUC/GAEZv3.0/soil_evaluation.html; last access: 7 June 2018, IIASA and FAO, 2012) and averaged over all crop species in the table.

Table 1. Overview of variables of the database used in the current study. Each plot for soil and vegetation analyses had a $10 \mathrm{~m}$ radius and was sampled once during the period 2003-2012. The (mostly managed) forests in the inventory represent a random sample of Swedish forests. Abbreviations: MAP: mean annual precipitation; TSUM: growing season temperature sum; SOC: soil organic carbon concentration; TEB: total exchangeable bases; $\mathrm{pH}_{\mathrm{W}}: \mathrm{pH}$ measured in water; $\mathrm{pH}_{\mathrm{KCl}}$ : $\mathrm{pH}$ measured in $\mathrm{KCl}$ solution; $\mathrm{TN}$ : total nitrogen concentration; soil $\mathrm{C}$ : $\mathrm{N}$ ratio: soil carbon-to-nitrogen ratio.

\begin{tabular}{|c|c|c|c|c|}
\hline Available & Location & Climate & Soil $^{b}$ & Vegetation \\
\hline Data & $\begin{array}{l}\text { Latitude }\left({ }^{\circ} \mathrm{N}\right) \\
\text { Longitude }\left({ }^{\circ} \mathrm{E}\right) \\
\text { Elevation }(\mathrm{m})\end{array}$ & $\begin{array}{l}\text { MAP (mm) } \\
\operatorname{TSUM}^{\mathrm{a}}\left({ }^{\circ} \mathrm{C} \text { days }\right)\end{array}$ & 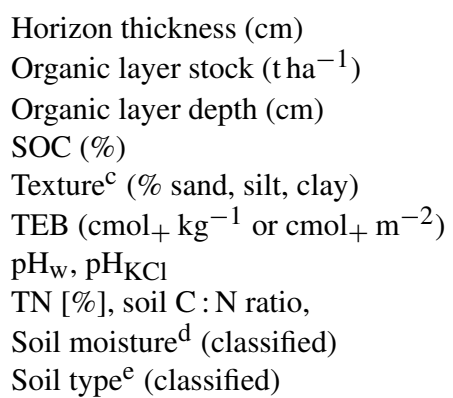 & $\begin{array}{l}\operatorname{Age}^{\mathrm{f}}(\mathrm{yr}) \\
\text { Tree species composition }(\%) \text { productivity } \\
\left(\mathrm{m}^{3} \mathrm{ha}^{-1} \mathrm{yr}^{-1}\right)\end{array}$ \\
\hline
\end{tabular}

\footnotetext{
a TSUM was calculated for each data point based on its latitude, longitude, and elevation. ${ }^{\mathrm{b}} n=3$; soil variables were determined using standard sampling and laboratory procedures (e.g., Olsson et al., 2009; Stendahl et al., 2010). ${ }^{\mathrm{c}}$ In an earlier version of the database, percentages of sand, silt, and clay were approximated from field-based soil texture class. ${ }^{\mathrm{d}}$ Soil moisture was determined in the field based on indicators (e.g., groundwater depth, moisture at the surface, ground vegetation, elevated tree trunks). The


World Reference Base for Soil Resources. ${ }^{\mathrm{f}}$ Stand age ranged between 1 and 350 years, with an average of 65 years. ${ }^{\mathrm{g}}$ Productivities (site quality) or mean annual volume increments (MAIs) over a full rotation were estimated based on height development curves. In situ productivities may be lower, depending on the management.
}

matrix with Pearson's $r$ as correlation coefficients for each variable pair.

Soil moisture and soil type (available as categorical variables) may act as confounding factors for associations between productivity and other soil properties (e.g., in wet soils, the rooting environment is anoxic and decomposition is inhibited (Olsson et al., 2009), leading to reduced productivity and accumulation of SOM). We therefore tested if the selected soil variables and normalized productivity differed among soil moisture classes (dry, fresh, fresh-moist, and moist, as available from the database and derived from a combination of indicators such as groundwater depth Olsson, 1999; Olsson et al., 2009) and the most common World Reference Base for Soil Resources-based soil types (Histosols, Gleysols, Regosols, Leptosols, and Podzols) using two-way ANOVA with soil moisture or type and tree species as fixed factors.
Numerous studies have shown the strong influence of $\mathrm{N}$ deposition on forest productivity (e.g., Laubhann et al., 2009; Solberg et al., 2009; de Vries et al., 2014; Binkley and Högberg, 2016; Wang et al., 2017). Although N deposition can influence the soil properties considered in our analyses, it may also influence productivity without immediate changes in these soil properties (i.e., there is a time lag - Novotny et al., 2015). In other words, for a given set of soil characteristics and climate, productivity may vary depending on $\mathrm{N}$ deposition, which would weaken the link between soil properties and normalized productivity. To verify whether $\mathrm{N}$ deposition confounded our analyses, we extracted $\mathrm{N}$ deposition data of 2015 from a map available at http://www.smhi.se/sgn0102/miljoovervakning/ kartvisare.php?lager=15DTOT_NOY__ ; last access: 7 June 2018 (Swedish Meteorological and Hydrological Institute, 2018), using the ArcGIS software (ESRI, 2011). We then tested whether $\mathrm{N}$ deposition correlated with productivity and 




Figure 2. Objectives and methods followed in the current paper. PRE refers to a regression model of productivity vs. climate and species (spp.); Question 1, Question 2, and Question 3 refer to the research questions. Performance of the adjusted nutrient metrics was evaluated against the entire database, and against five nutrient availability gradients, selected from the database (Fig. S2).

soil variables, using Pearson's correlation coefficient $(r)$, and performed regression analyses on normalized productivity vs. $\mathrm{N}$ deposition, stratified by soil moisture and type.

\subsubsection{Question 1 - normalized productivity vs. single and combined soil variables}

Simple regression analysis was used to determine the relationship between single soil variables and normalized productivity. To test the robustness of the observed relationships in the absence of potentially confounding effects of soil moisture and type, we performed these analyses on all data, and on the data stratified by soil moisture and soil type. Then, we tested which combination of continuous soil variables best explained variation in normalized productivity across Sweden (multiple regression analysis). Starting from the full model containing all explanatory variables, the least significant term was removed, resulting in a simplified model. Performance of the full and simplified models was then compared using the mean squared error (mse), based on cross validation (package DAAG - Maindonald and Braun, 2015). We repeated this model simplification procedure until mse stopped decreasing. Interaction effects up to the first order were added if suggested by regression trees (package tree - Ripley, 2015). For method 1 (Fig. 3), first-order interactions of continuous variables with region as a factor (levels:
$\mathrm{N}, \mathrm{M}, \mathrm{S}$ ) were included in the selection procedure (i.e., an ANCOVA was used for this approach).

\subsubsection{Question 2 - evaluation of the IIASA metric}

Irrespective of the method applied, a well-functioning nutrient availability metric would be recognized by a clear, positive relationship with productivity. We used linear model analysis to test the significance of the relationship between the metric and normalized productivity, and to determine its explanatory power $\left(R^{2}\right)$. To test whether the variables included in the metric were accurately implemented, we also examined the correlation between the residuals of this linear model and each of the variables included in the metric ( $\mathrm{SOC}$, soil texture, $\mathrm{TEB}$, and $\mathrm{pH}_{\mathrm{w}}$ ). A significant correlation suggests that the soil variable under consideration is not optimally implemented in the metric.

\subsubsection{Question 3 - adjustments of the IIASA metric}

Outcomes of Question 1 indicated which soil variables best explained variation in normalized productivity. This information was further used to (i) assess if the relationships for variables already included in the IIASA metric should be altered, (ii) remove soil variables from the metric if their empirical associations with normalized productivity were opposite from their relationships in the original IIASA metric, which would complicate parameterization, and (iii) include 


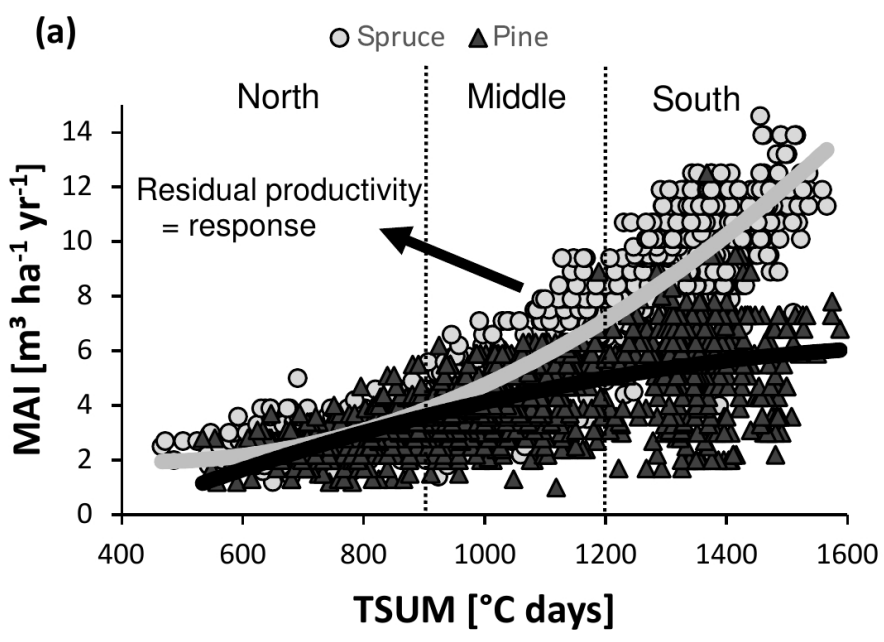

(b) Actual/attainable MA for spruce forests across Sweden

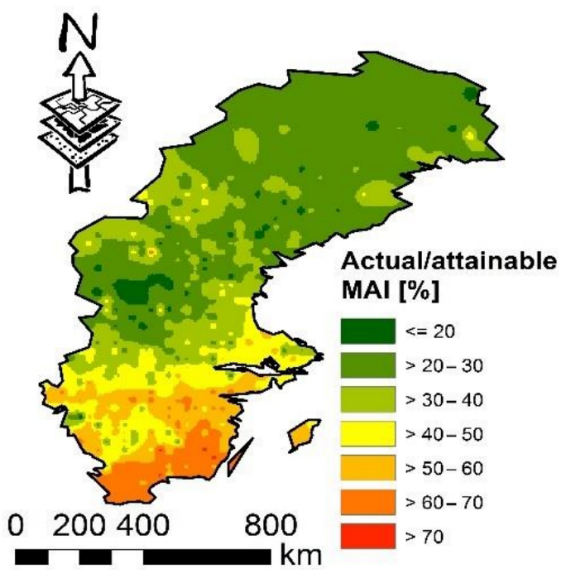

Figure 3. Normalized productivity was calculated in two alternative ways. (a) In method 1, residual values were taken from a regression model, explaining variation in mean annual increments (MAIs) by climate (growing season temperature sum or TSUM and precipitation) and species. The selection procedure, equation, and parameter estimates are given in the Supplement (respectively Tables S1 and S2 and Eq. S1 in the Supplement). In order to avoid heteroscedasticity-induced artifacts, the dataset was split into northern (TSUM $<900{ }^{\circ} \mathrm{C}$ days), middle $\left(900^{\circ} \mathrm{C}\right.$ days $<\mathrm{TSUM}<1200^{\circ} \mathrm{C}$ days), and southern (TSUM $>1200^{\circ} \mathrm{C}$ days) regions for this approach. (b) In method 2 , actual productivities for spruce were divided by theoretically attainable productivities, provided by Bergh et al. (2005).

additional soil variables to improve performance of the metric. Two new metrics were developed: "adjusted metric 1" and "adjusted metric 2", referring to the respective methods of normalizing productivity (Fig. 3). As a starting point for adjusted metric 1, half of the dataset from southern Sweden (where productivity varied most; see Fig 3a) was used as a calibration set to derive regression equations, while half of the complete national dataset for spruce served as a calibration set for adjusted metric 2 . The best predictors of normalized productivity as indicated by the analyses in Question 1 were then adopted as partial metric scores (see the original Eqs. 6-9). Moreover, for adjusted metric 1, the minimum and maximum normalized productivities observed in southern Sweden were included as lower and upper boundaries to the partial metric scores to avoid possible unrealistic values for future applications to other datasets. For method 2, the minima and maxima were, as in the IIASA metric, set to 0 and $100 \%$, respectively (units for this metric (\%) remained the same as in the original IIASA metric, while for new metric 1 , the unit was $\left.\left(\mathrm{m}^{3} \mathrm{ha}^{-1} \mathrm{yr}^{-1}\right)\right)$. Finally, the two improved metrics for nutrient availability were calculated as in Eq. (10).

Performance of the adjusted metrics was evaluated by (i) testing normalized productivity in the database against the metrics and inspecting the implementation of the variables, and by (ii) testing productivity against the metrics and examining variable implementation for five manually selected local gradients in nutrient availability. For (i), the metrics were thus evaluated as described for the IIASA metric under Question 2, with the exceptions that validation datasets were used (i.e., the data that were used for developing the metrics were not included for the evaluations) and that the same analyses were also performed after stratifying by soil moisture and type to assess robustness. For (ii), two gradients with spruce, and three gradients with pine (locations indicated in Fig. S2) were selected in ArcGIS (ESRI, 2011). Each of these gradients included at least 40 data points from the Swedish database that (i) were located in the same region, without showing substantial spatial variation in climate and (ii) showed high spatial variation in soil moisture, TEB, or productivity (we also searched specifically for clear soil $\mathrm{C}: \mathrm{N}$ gradients, but found none for which climate did not vary; variables like soil $\mathrm{C}: \mathrm{N}$ or SOC did however sufficiently vary within the five selected gradients: $\leq 16.8-\geq 32.2$ and $\leq 1.6-\geq 48.5 \%$, respectively). We thus not only evaluated the adjusted metrics against normalized productivity across the complete database but also tested their performance for local gradients, which offered the advantage that no normalization of productivity for climate was needed.

We examined the validity of the linear models' assumptions (linearity, normality of residuals, no influential outliers, homoscedasticity) with standard functions of R ( R Core Team, 2015), including diagnostic plots. Moreover, for all regressions, potential nonlinearities were detected with histograms of all variables' distributions and generalized additive models from the mgcv package (Wood, 2006). Data were $\log$ transformed if their distribution was right-skewed, while polynomial (e.g., quadratic) functions were included in the model selection procedure where the general additive models suggested nonlinear patterns. The variance infla- 
(a)

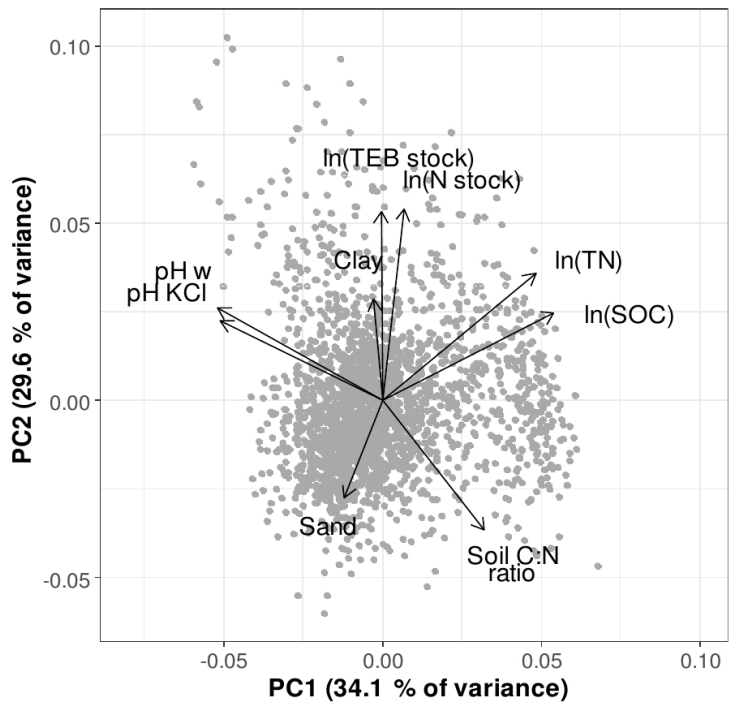

(b)

\begin{tabular}{|c|c|c|c|c|c|c|c|c|c|}
\hline $\begin{array}{l}\text { Soil } \\
\text { variable }\end{array}$ & $\ln \mathrm{TN}$ & $\ln \mathrm{N}$ stock & $\begin{array}{l}\text { Soil C:N } \\
\text { ratio }\end{array}$ & Sand & Clay & $\begin{array}{l}\text { ln TEB } \\
\text { stock }\end{array}$ & $\mathrm{pH}_{\mathrm{w}}$ & $\mathrm{pH} \mathrm{KCl}_{\mathrm{K}}$ & $\begin{array}{l}\ln \mathrm{N} \\
\text { dep. }\end{array}$ \\
\hline $\ln \mathrm{SOC}$ & +0.97 & +0.38 & +0.39 & -0.18 & +0.05 & +0.33 & -0.45 & -0.45 & +0.30 \\
\hline $\ln \mathrm{TN}$ & & +0.52 & +0.15 & $\overline{-0.21}$ & +0.10 & +0.43 & $\overline{-0.34}$ & $\overline{-0.34}$ & $\overline{+0.34}$ \\
\hline $\ln \mathrm{N}$ stock & & & -0.42 & $\overline{-0.16}$ & $\overline{+0.19}$ & +0.58 & $\overline{+0.11}$ & $\overline{+0.12}$ & +0.39 \\
\hline Soil C:N ratio & & & & +0.06 & -0.16 & -0.23 & -0.52 & -0.53 & -0.10 \\
\hline Sand & & & & & -0.44 & -0.20 & +0.01 & +0.03 & -0.21 \\
\hline Clay & & & & & & +0.21 & +0.11 & +0.10 & $\overline{+0.13}$ \\
\hline In TEB stock & & & & & & & +0.39 & +0.22 & +0.13 \\
\hline $\mathrm{pH}_{\mathrm{w}}$ & & & & & & & & $\overline{+0.89}$ & $\underline{-0.18}$ \\
\hline $\mathrm{pH}$ & & & & & & & & & $\overline{-0.12}$ \\
\hline
\end{tabular}

Figure 4. Correlation structure of a set of potential key soil variables for a soil depth of $0-20 \mathrm{~cm}$. Panel (a) shows the principal component analysis (PCA) biplot (SD for PC1 $=1.75$, SD for PC2 $=1.63$ ); panel (b) shows the correlation matrix, showing Pearson's $r$ for the variable pairs, including correlations with nitrogen deposition. Underlined correlations were significant. Abbreviations: SOC: soil organic carbon concentration $(\%)$; TN: soil total nitrogen $(\%)$; $\mathrm{N}$ stock: amount of nitrogen in the layer $\left(\mathrm{g} \mathrm{m}^{-2}\right)$; Soil $\mathrm{C}$ : $\mathrm{N}$ ratio: soil carbon-to-nitrogen ratio; Sand: percentage of sand in the mineral soil; Clay: percentage of clay in the mineral soil; TEB: total exchangeable bases $\left(\mathrm{cmol}_{+} \mathrm{m}^{-2}\right.$ ); $\mathrm{pH}_{\mathrm{w}}: \mathrm{pH}$ measured in water; $\mathrm{pH}_{\mathrm{KCl}}: \mathrm{pH}$ measured in $\mathrm{KCl}$ solution; $\mathrm{N}$ dep: nitrogen deposition.

tion factor (package car - Fox and Weisberg, 2011) assessed possible multicollinearity. Whenever confidence intervals are given, they represent standard errors of the mean (s.e.m.). For all analyses, $\alpha=0.05$ was taken as the significance level, whereas $P$ values between 0.05 and 0.10 were considered to be borderline significant.

\section{Results}

\subsection{Identifying potentially confounding factors}

Correlations among soil properties and nutrients were investigated to verify if any of the variables could be excluded in the subsequent analyses due to redundancy. In this database, $\mathrm{pH}_{\mathrm{w}}$ and $\mathrm{pH}_{\mathrm{KCl}}$ were strongly correlated. As $\mathrm{pH}_{\mathrm{KCl}}$ has the practical advantage of showing less seasonal variation than $\mathrm{pH}_{\mathrm{w}}$ (Soil Survey Staff, 2014), we opted to use only $\mathrm{pH}$ in the analyses for research Question 1. Similarly, TN and SOC largely shared the same information. We included SOC in the analyses and discarded TN because SOC is a component of the IIASA metric of constraints on nutrient availability. Moreover, soil organic matter acts as a nutrient store and provides cation and anion exchange sites, while $\mathrm{TN}$ is merely correlated to SOM but only a (small) proportion of total $\mathrm{N}$ is available to the plants. Collinearity among other variables was minor ( $\mid$ Pearson's $r \mid<0.65$; Fig. 4), and they were thus all included in the analysis.

Relationships between soil variables and normalized productivity might vary depending on factors such as soil moisture and soil type. Therefore, we first examined how these factors influence soil properties and normalized productivity. Soil moisture, for example, may influence nutrient availability of ecosystems by - among others - affecting the rate of decomposition, and consequently change other soil char- 
(a)
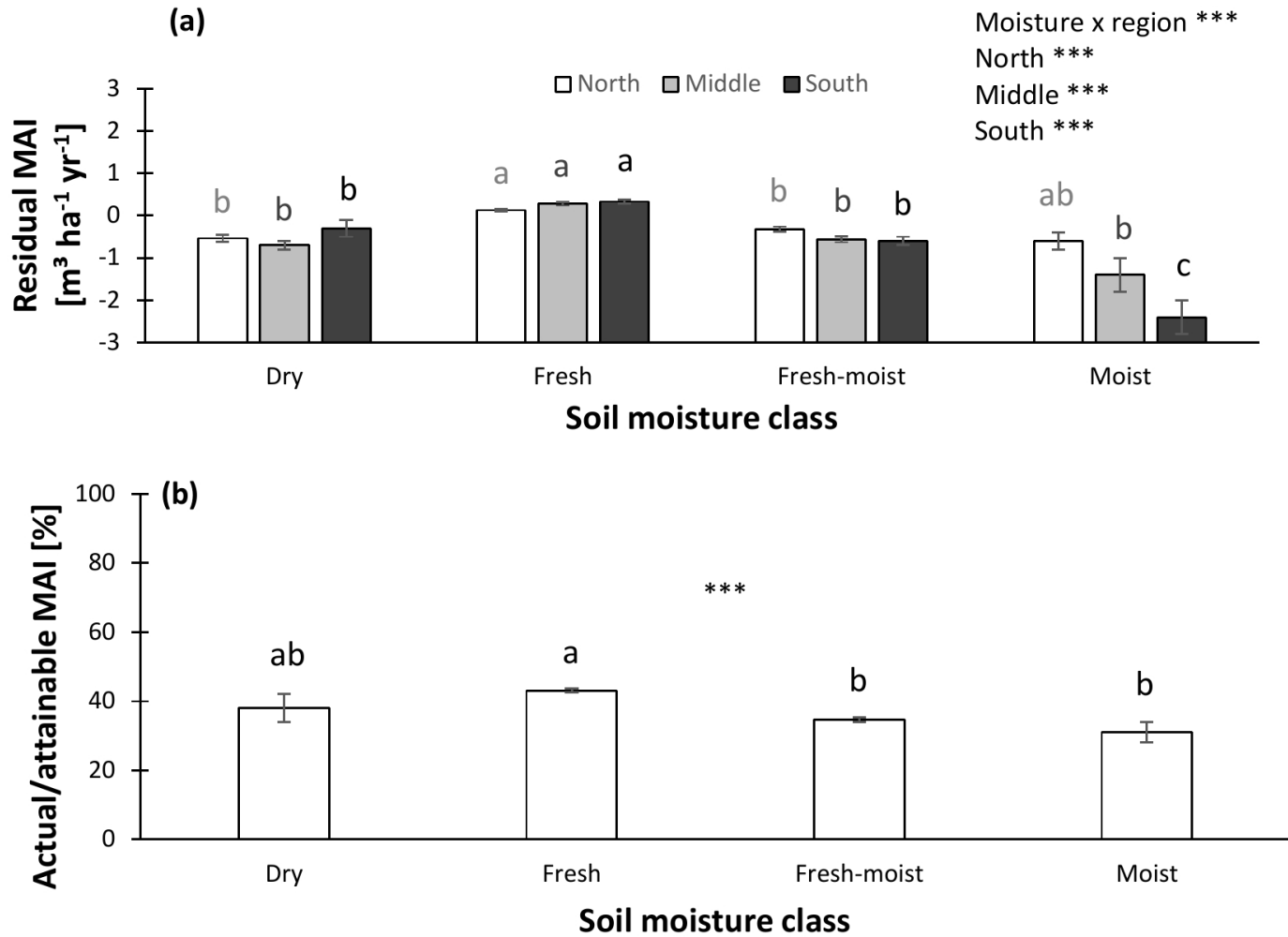

Figure 5. Normalized productivity per soil moisture class. (a) Productivity normalized following method 1 (residual mean annual increment MAI) vs. soil moisture. (b) Productivity normalized following method 2 (actual / attainable mean annual increment - MAI) vs. soil moisture. In panel (a), separate analyses were performed for northern, middle, and southern Sweden, as the moisture effects differed among regions. *** Indicates significant differences at the $P<0.01$ level. Error bars represent the standard error of the mean (s.e.m).

acteristics. In the database, each forest was originally assigned to a soil moisture category. Using these categories, we found that $\mathrm{SOC}$ and the soil $\mathrm{C}: \mathrm{N}$ ratio increased from dry to moist. A similar trend was observed for TEB, while the sand fraction and $\mathrm{pH}_{\mathrm{KCl}}$ decreased from dry to moist. For clay, no significant differences among soil moisture classes occurred (Fig. S3). Lastly, normalized productivity was highest in the fresh soil moisture class and lowest for the wettest forests (Fig. 5). This pattern was most pronounced in southern Sweden (north $-F_{3,568}=22.43, P<0.01$; middle $F_{4,844}=39.47, P<0.01$; south $-F_{4,1056}=35.23, P<0.01$; moisture $x$ region $-F_{7,2468}=3.77, P<0.01$ ).

Soil properties not only differed among soil moisture classes, but also among soil types. Especially Histosols and Podzols could be distinguished from the other soils: Histosols (which largely overlapped with the wet soil moisture classes) were characterized by a low $\mathrm{pH}_{\mathrm{KCl}}$ and high SOC and soil $\mathrm{C}: \mathrm{N}$ ratio, while Podzols were sandy and had a low TEB stock (Fig. S4). Differences in normalized productivity among soil types were observed as well. Histosols in particular showed reduced productivities compared to other soil types (Fig. 6). Hence, the wetness of a site and its type of soil (partly in parallel with wetness) could confound observed patterns in productivity associated with the soil variables and are therefore taken into account in further analyses and their interpretation.

In addition to soil moisture and soil type, $\mathrm{N}$ deposition may also confound associations between normalized productivity and soil data. In our Swedish database, $\mathrm{N}$ deposition correlated significantly with all soil variables. Especially TN and SOC correlated positively with $\mathrm{N}$ deposition (Fig. 4b). N deposition was also strongly positively correlated with productivity (Pearson's $r=0.73$ ); both variables increased from north to south, as did the growing season temperature sum (which was therefore also highly correlated with (ln) $\mathrm{N}$ deposition - Pearson's $r=0.91$ ). However, $\mathrm{N}$ deposition did generally not have a significant effect on productivity normalized with method 1 (i.e., residual productivity), while with method 2 (i.e., actual / attainable productivity), there was a strong positive relationship with $\mathrm{N}$ deposition. The increasing $\mathrm{N}$ deposition along the north-south gradient in Sweden (e.g., Olsson et al., 2009) should thus be kept in mind when interpreting effects of soil variables on productivity when normalized following method 2 . 

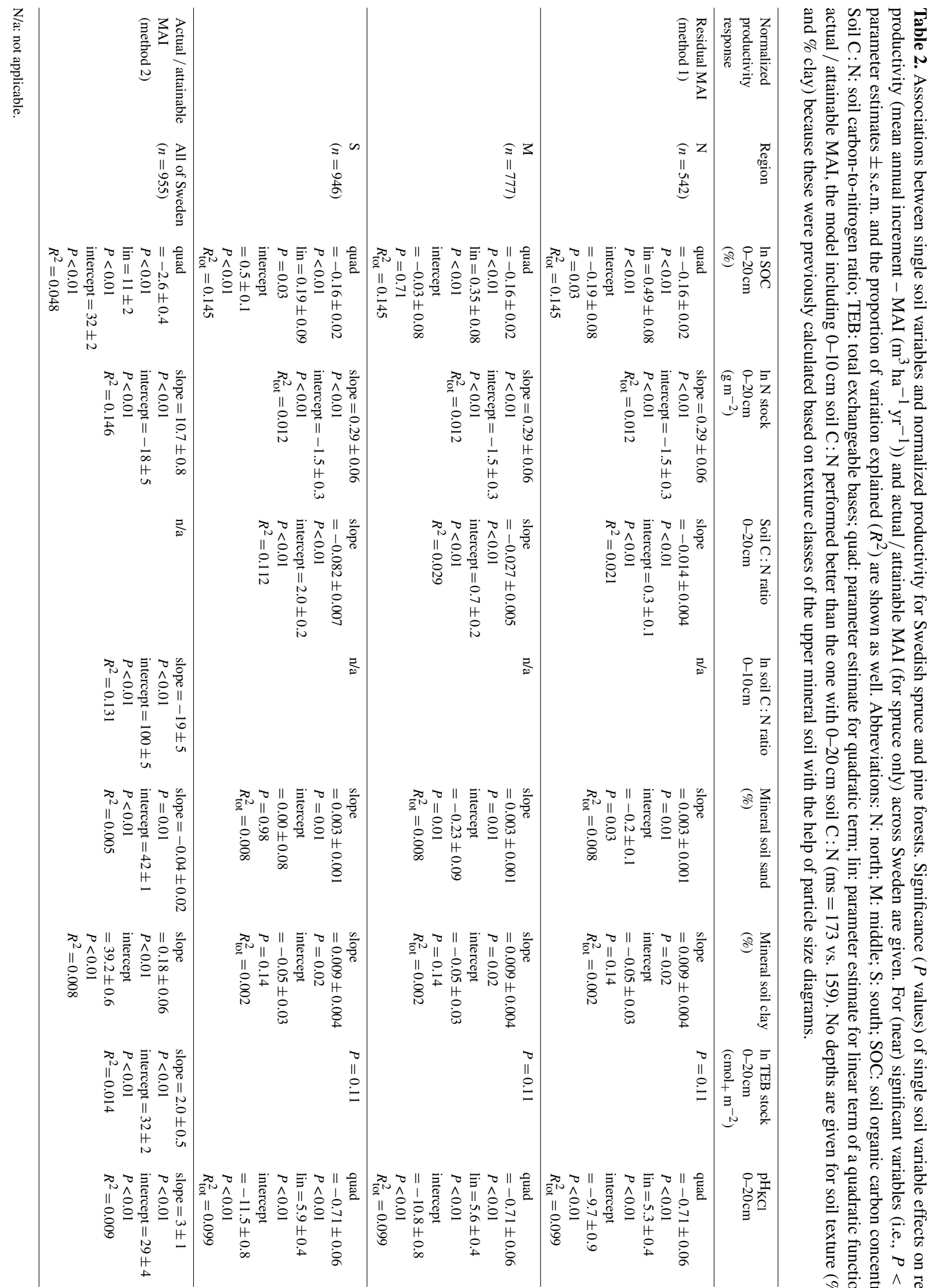

至

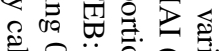

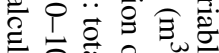

产。

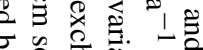

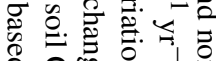

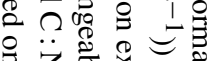

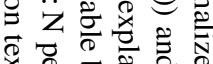

要

ह

융



o

言

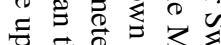

ट

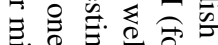

¿

풍

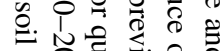

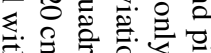

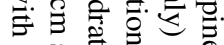

후유.

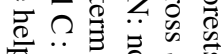

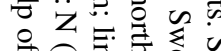

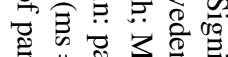

$\|$. 119

施

n.

0.

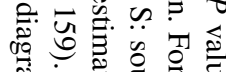

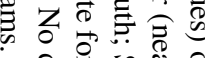

के

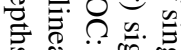

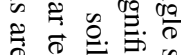

穴. 品

@

氝. 气

을 웧

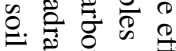

व

言 局吕 0

के 웅 숭

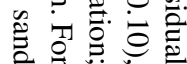




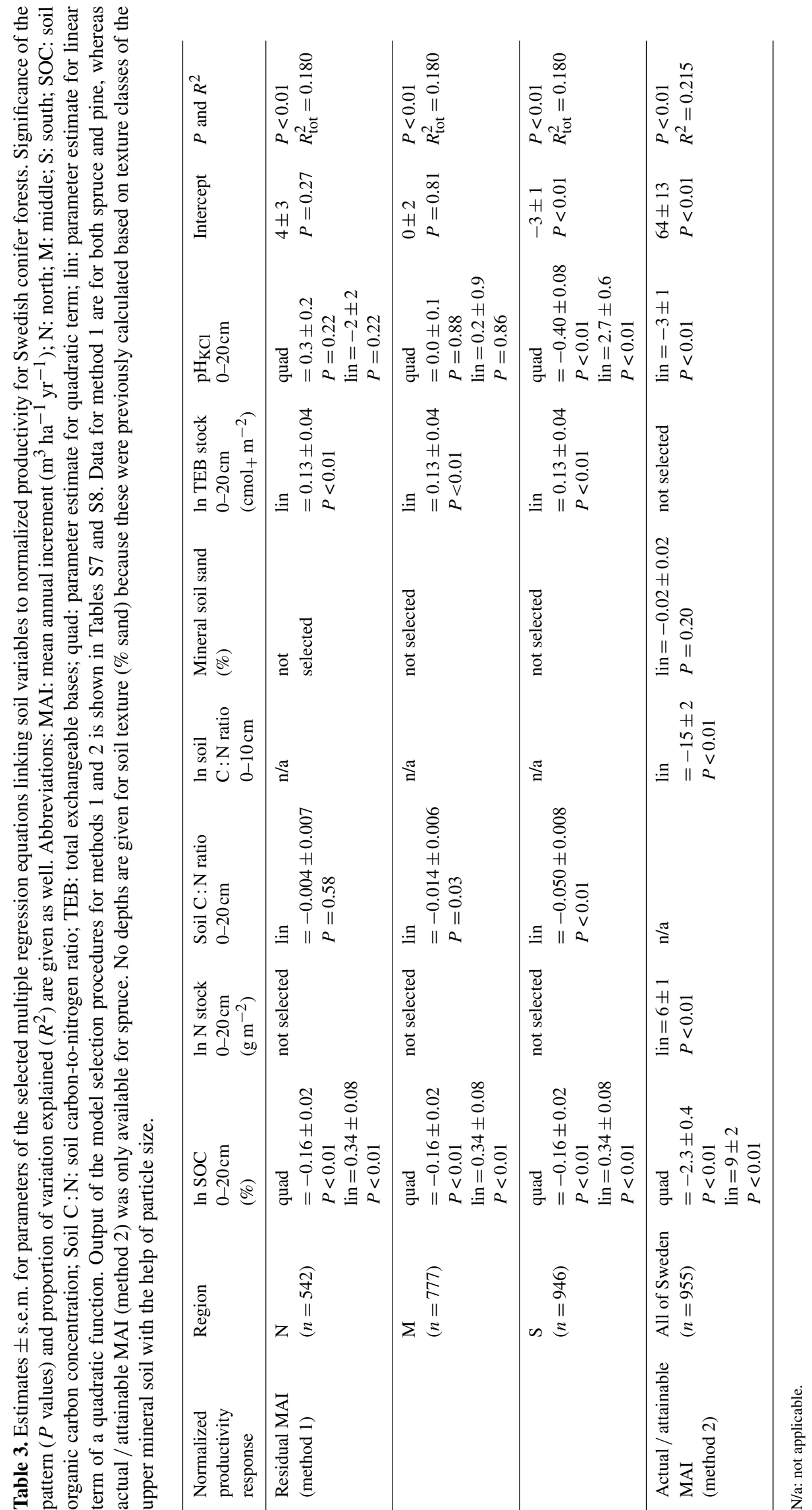



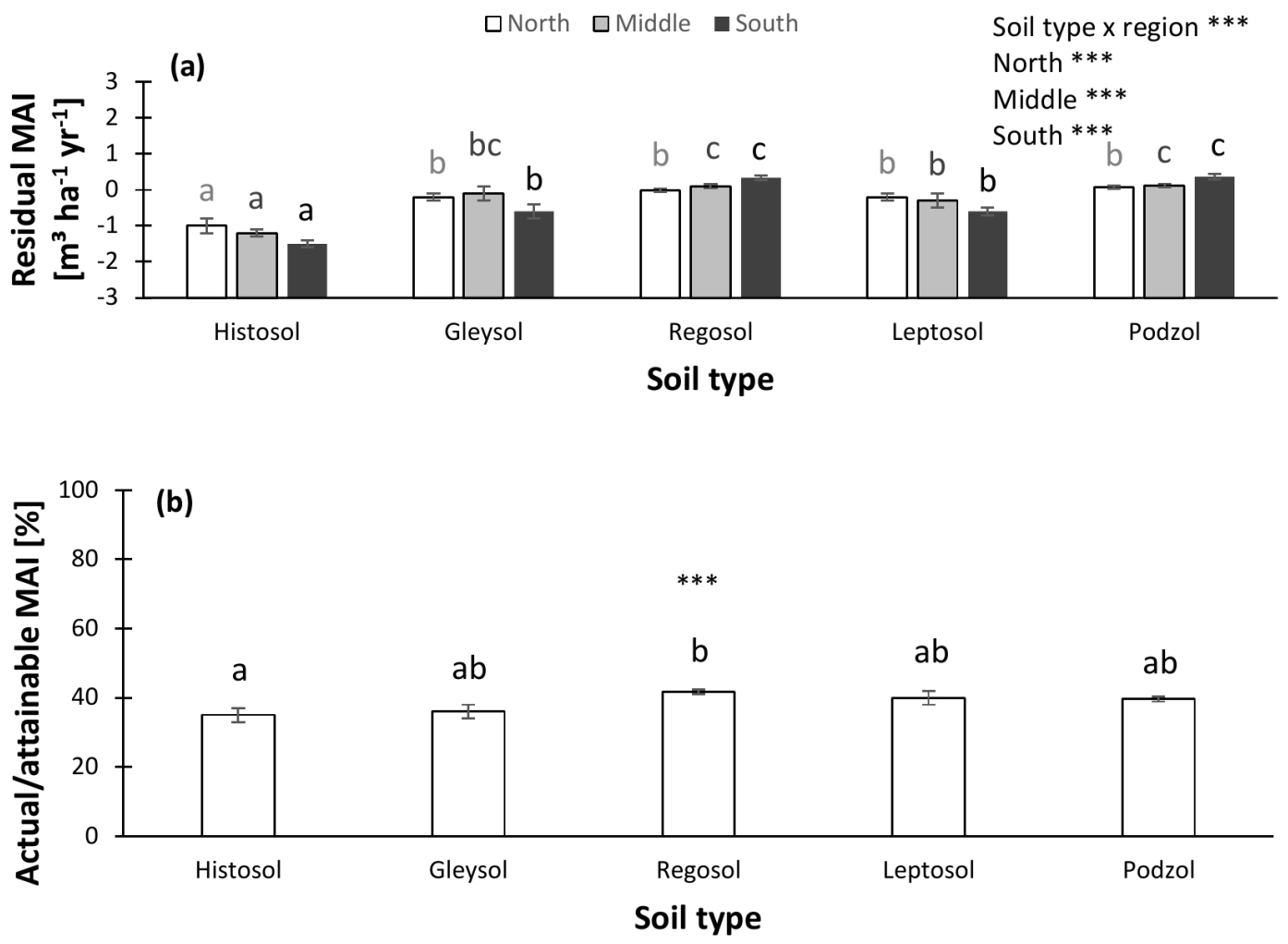

Figure 6. Normalized productivity per soil type. (a) Productivity normalized following method 1 (residual mean annual increment - MAI) vs. soil type. (b) Productivity normalized following method 2 (actual / attainable mean annual increment - MAI for spruce) vs. soil type. In panel (a), separate analyses were performed for northern, middle, and southern Sweden, as the soil type effects differed among regions. *** Indicates significant differences at the $P<0.01$ level. Error bars represent the s.e.m.
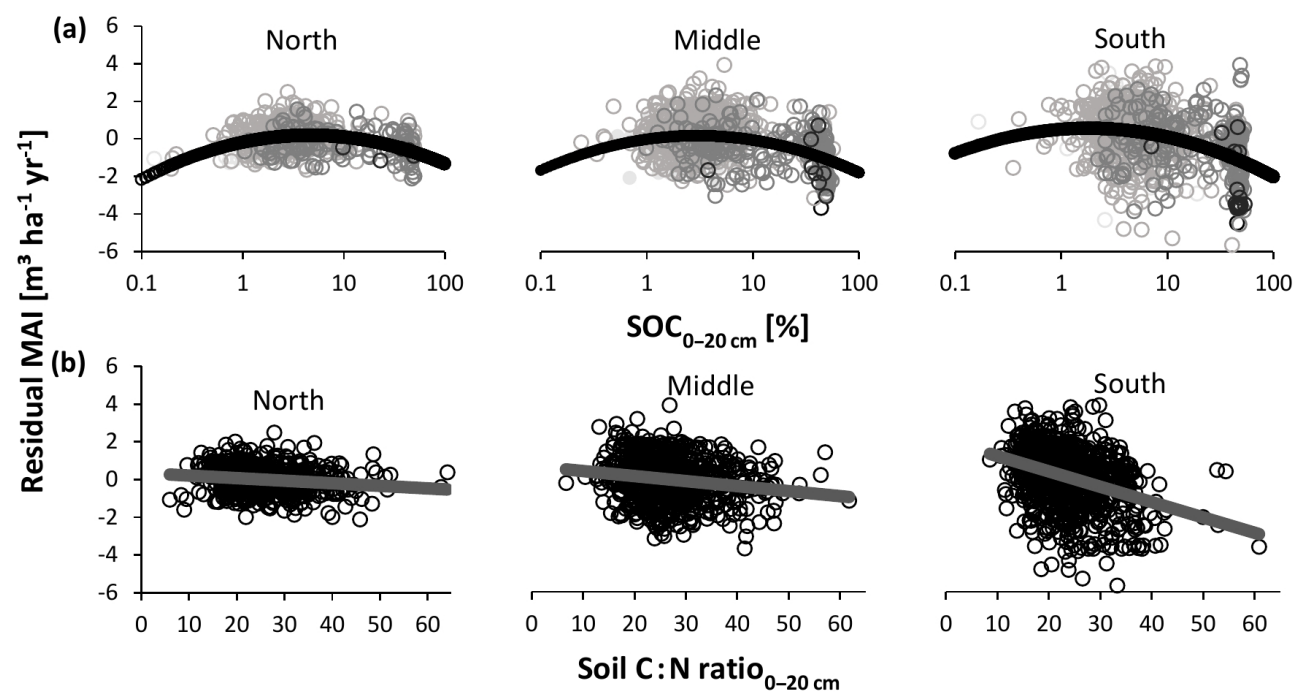

Figure 7. Relationship between normalized productivity following method 1 (residual mean annual increment - MAI); (a) log-transformed soil organic carbon concentration (SOC); (b) soil carbon-to-nitrogen $(\mathrm{C}: \mathrm{N})$ ratio at a depth of 0-20 cm. Separate analyses were performed for northern, middle, and southern Sweden, as the SOC and C:N effects differed among regions. Point darkness in (a) represents soil moisture (darker: moister). Statistics corresponding to the panels are presented in Table 2. Note that the horizontal axis for SOC covers a broader range here than in Fig. 1, as SOC varied widely in the Swedish database. 

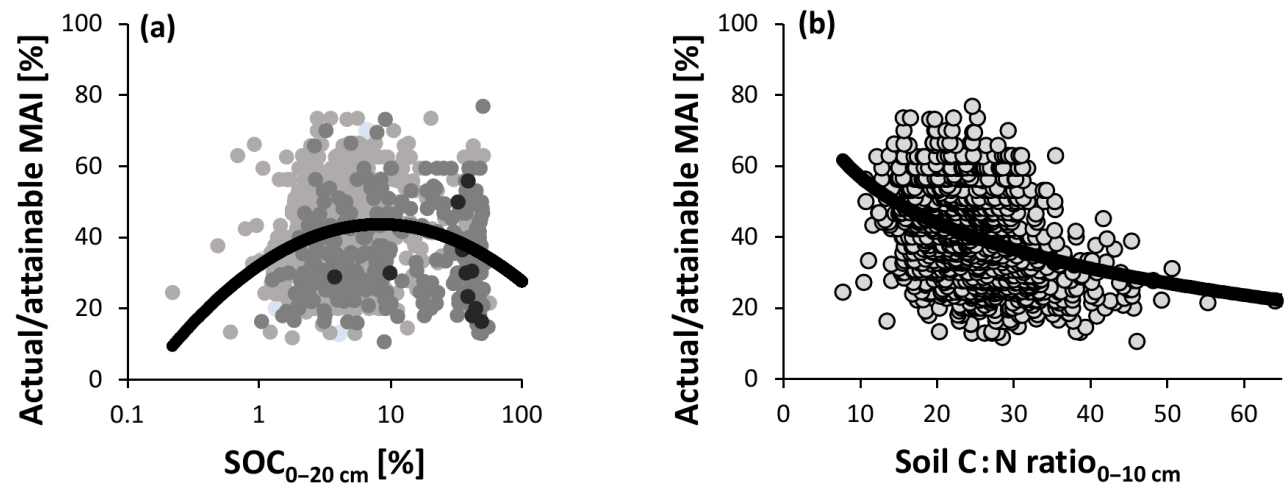

Figure 8. Relationship between normalized productivity following method 2 (actual / attainable mean annual increment - MAI for spruce); (a) log-transformed soil organic carbon concentration (SOC); (b) soil carbon-to-nitrogen ratio (C: N). Point darkness in (a) represents soil moisture (darker: moister). Statistics corresponding to the panels are presented in Table 2. Note that the horizontal axis for SOC covers a broader range here than in Fig. 1, as SOC varied widely in the Swedish database. Also note that the $\mathrm{C}: \mathrm{N}$ ratio of the upper $10 \mathrm{~cm}$ was used instead of the upper $20 \mathrm{~cm}$ here, owing to a better description of variation in the response variable. Even though the $\mathrm{C}: \mathrm{N}$ ratio roughly decreased southwards (Fig. S1d), it was only weakly correlated with the growing season temperature sum $\left(r=-0.13\right.$ for $\mathrm{C}: \mathrm{N}_{0-20 \mathrm{~cm}}$ and $r=-0.28$ for $\mathrm{C}: \mathrm{N}_{0-10 \mathrm{~cm}}$ ).

\subsection{Question 1 - normalized productivity vs. single and combined soil variables}

In order to elucidate how soil variables affect nutrient availabilities across Sweden, we used their single and combined relationships with normalized productivity. For method 1, we found that most single soil variables were significantly related to normalized productivity (Table $2 ; R^{2}$ ranged between 0.002 and 0.146). For both SOC (Fig. 7a) and $\mathrm{pH}_{\mathrm{KCl}}$, the relationship with normalized productivity showed an optimum (i.e., an empirical quadratic relationship fit better than a linear model). Normalized productivity was significantly negatively correlated with the soil $\mathrm{C}: \mathrm{N}$ ratio (Fig. 7b), for which the effect became more pronounced towards the south (i.e., slopes and $R^{2}$ values increased; $F_{2.2274}=34.23, P<0.01$ ). Finally, associations with soil $\mathrm{N}$ stocks and clay were weak (but significantly positive). The strongest relationships were found for normalized productivity versus $\mathrm{SOC}, \mathrm{pH}_{\mathrm{KCl}}$, and soil $\mathrm{C}: \mathrm{N}$ ratio and consequently these were among the variables selected for the model with multiple covariates (Table $3)$.

Results of method 2 were qualitatively similar to those of the other approach for SOC (Fig. 8a), N stock, soil C:N ratio (Fig. 8b), clay fraction, and TEB, although the $\mathrm{N}$ stock explained a larger proportion of the variation here and the curve for actual / attainable productivity decreased logarithmically rather than linearly with increasing $\mathrm{C}: \mathrm{N}$ ratio. However, the function for $\mathrm{pH}_{\mathrm{KCl}}$ did not show an optimum, but was linear with a significantly positive slope (Table 2 ). In summary, SOC and the soil $\mathrm{C}: \mathrm{N}$ ratio were the only soil factors that showed a similar trend, according both methods with an $R^{2}$ of at least a few percent, and were thus included in the multiple regression models for both methods 1 and 2 (these mod- els also included other variables resulting from the stepwise regression analysis; Table 3).

Since soil moisture and soil type influenced both soil properties and normalized productivity, we also stratified the analyses above by these factors. In general, these separate analyses confirmed the robustness of the observed patterns across the database (despite low $R^{2} \mathrm{~s}$ ), as the results and parameter estimates were similar to those of the previous analysis (Tables S5 and S6).

\subsection{Question 2 - evaluation of the IIASA metric}

Both methods agreed on the poor performance of the IIASA metric to elucidate patterns in nutrient availability, as the weakly positive correlation between normalized productivity and the metric was rarely significant, and explained $<1 \%$ of the variation in normalized productivity in northern Sweden for method 1 (Fig. 9). Residual values of the relationship between normalized productivity of method 1 and the metric score (Fig. 9a) were significantly associated with all four input variables of the metric ( $\mathrm{SOC}$, soil texture, TEB, and $\mathrm{pH}_{\mathrm{w}}$ - Table S9). SOC and TEB correlated negatively with these residuals, while sand was significantly positively related to these same residuals, and productivities at low $\mathrm{pH}_{\mathrm{w}}$ were overestimated (the empirical quadratic functions were concave; not shown in Table S9). Residuals of method 2 (Fig. 9b) confirmed the negative trend with TEB but showed no statistically significant relationship with $\mathrm{SOC}$, texture, or $\mathrm{pH}_{\mathrm{w}}$ (Table S9). Overall, the fact that residuals were still correlated with the variables in the metric suggests that the input variables were not optimally implemented in the formula. 

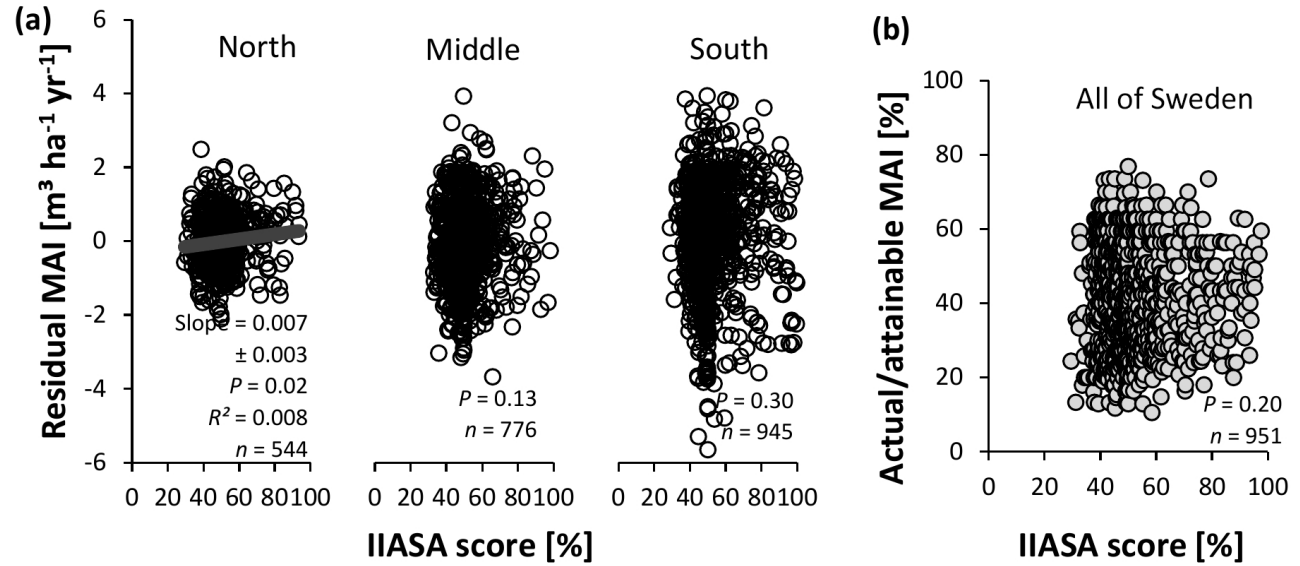

Figure 9. Evaluation of the IIASA metric of constraints on nutrient availability for Swedish conifer forests. (a) Method 1 - association with residual mean annual increments (MAIs) of the productivity-climate regression model (Fig. 3a, Eq. S1 and Table S2), distinguishing northern, middle, and southern Sweden. (b) Method 2 - association with actual / attainable MAI for the entire Swedish land area (Fig. 3b). Full line: significant slope $(P<0.05)$.

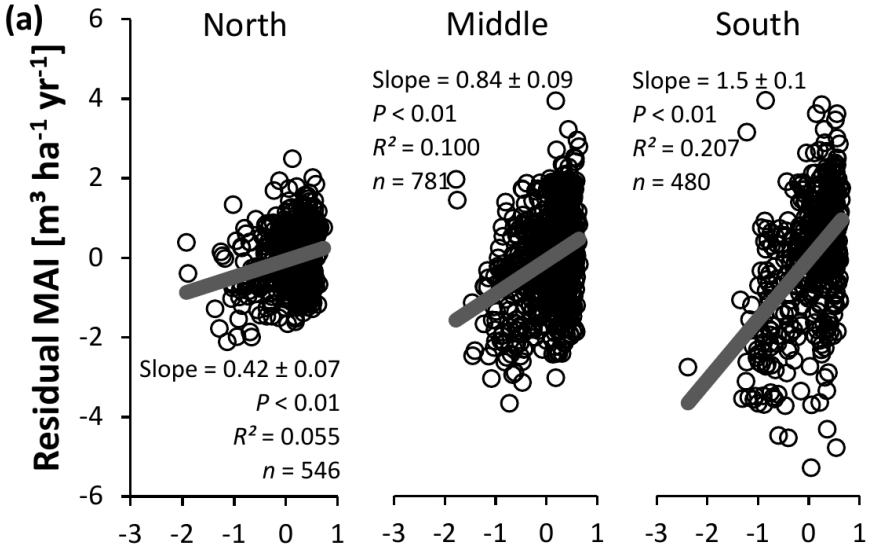

Adjusted metric $1\left[\mathrm{~m}^{3} \mathrm{ha}^{-1} \mathrm{yr}^{-1}\right]$

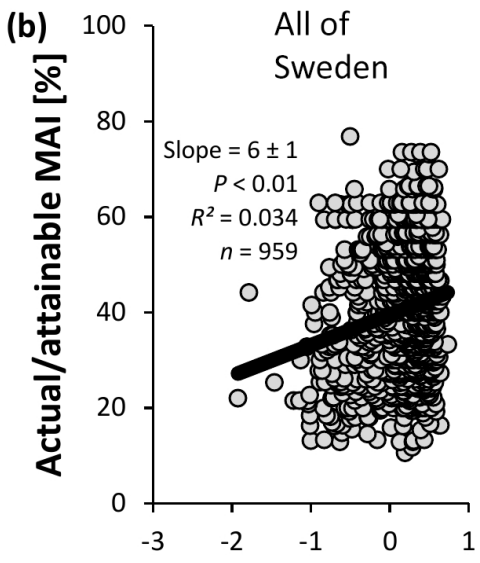

Adjusted metric 1 $\left[\mathrm{m}^{3} \mathrm{ha}^{-1} \mathrm{yr}^{-1}\right]$

Figure 10. Evaluation of adjusted nutrient availability metric 1 for Swedish conifer forests. (a) Method 1 - association with residual mean annual increments (MAIs) of the productivity-climate regression model (Fig. 3a, Eq. S1 and Table S2), distinguishing northern, middle, and southern Sweden. (b) Method 2 - association with actual / attainable MAI (Fig. 3b) for the entire Swedish land area. Full line: significant slope $(P<0.05)$.

\subsection{Question 3 - adjustments of the IIASA metric}

From the statistical analyses for Question 1, we deduce that SOC, soil $\mathrm{C}: \mathrm{N}$, and $\mathrm{pH}$ each play a role in influencing nutrient availability in Sweden. Based on their relationships with normalized productivity in southern Sweden according to method 1 (Table S10), and in all of Sweden according to method 2 (Table S11), the following formulae were implemented in two adjusted nutrient availability metrics (Figs. S5 and S6):

SOC Score $\left[\mathrm{m}^{3} \mathrm{ha}^{-1} \mathrm{yr}^{-1}\right]$

$$
\begin{aligned}
& \quad=\max \left(-0.18 \cdot\left(\ln \left(\mathrm{SOC}_{0-20 \mathrm{~cm}}[\%]\right)\right.\right. \\
& \left.\quad-\ln (2.3))^{2}+0.525,-5.65\right) \\
& \text { Soil C : N Score }\left[\mathrm{m}^{3} \mathrm{ha}^{-1} \mathrm{yr}^{-1}\right] \\
& \quad=\max \left(-0.08 \cdot \mathrm{C}: \mathrm{N}_{0-20 \mathrm{~cm}}+2.1,-5.65\right), \\
& \text { pH Score }\left[\mathrm{m}^{3} \mathrm{ha}^{-1} \mathrm{yr}^{-1}\right] \\
& =\max \left(-0.9 \cdot\left(\mathrm{pH}_{\mathrm{w}, 0-20 \mathrm{~cm}}-4.67\right)^{2}+0.6,-5.65\right),
\end{aligned}
$$



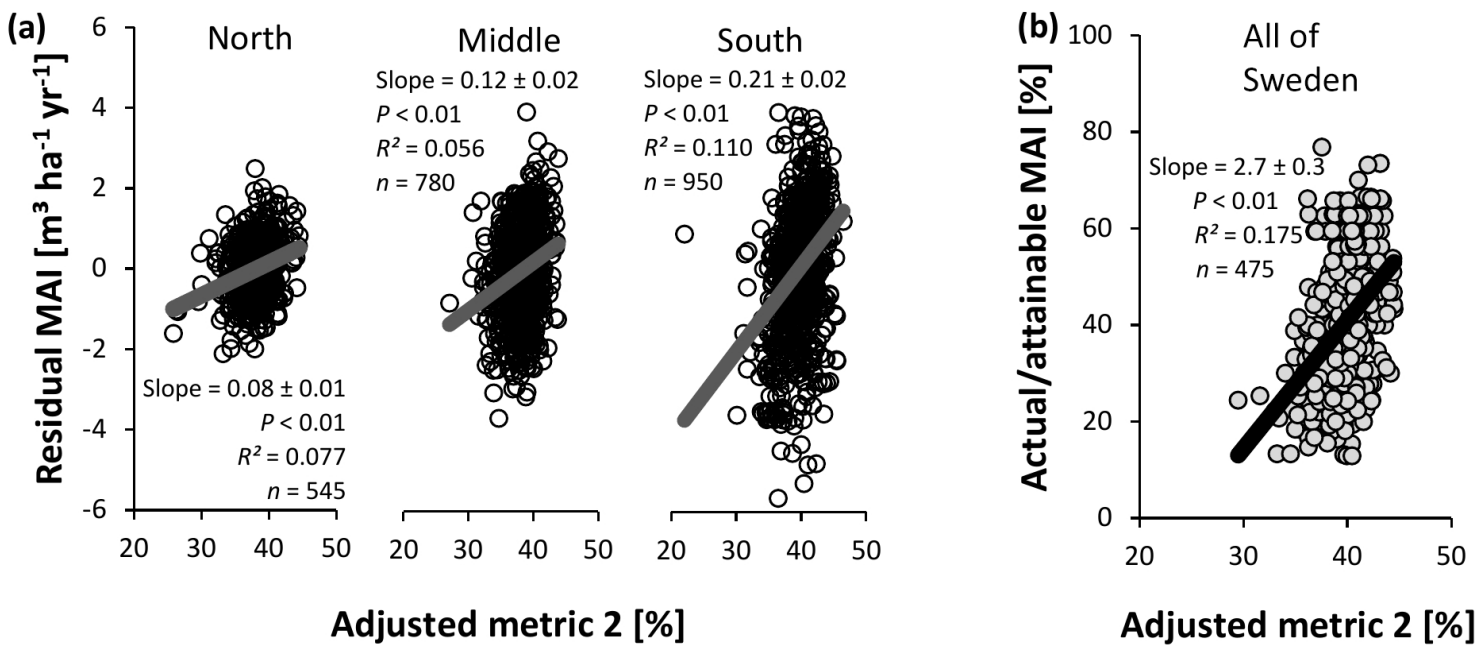

Figure 11. Evaluation of adjusted nutrient availability metric 2 for Swedish conifer forests. (a) Method 1 - association with residual mean annual increments (MAIs) of the productivity-climate regression model (Fig. 3a, Eq. S1 and Table S2), distinguishing northern, middle, and southern Sweden. (b) Method 2 - association with actual / attainable MAI (Fig. 3b) for the entire Swedish land area. Full line: significant slope $(P<0.05)$.

for the metric based on method 1 (adjusted metric 1), and

$$
\begin{aligned}
& \text { SOC Score[\%] }=\max \left(-2.8 \cdot\left(\ln \left(\operatorname{SOC}_{0-20 \mathrm{~cm}}[\%]\right)\right)\right. \\
& \left.(-\ln (8.1))^{2}+43.5,0\right)
\end{aligned}
$$

Soil C : N Score[\%]

$$
\begin{gathered}
=\max \left(-19 \cdot \ln \left(\mathrm{C}: \mathrm{N}_{0-10 \mathrm{~cm}}\right)+102,0\right), \\
\mathrm{pH} \text { Score }[\%]=\max \left(2 \cdot \mathrm{pH}_{\mathrm{w}, 0-20 \mathrm{~cm}}+31,0\right),
\end{gathered}
$$

for the metric based on method 2 (adjusted metric 2).

In the same way as for the IIASA metric, Eqs. (11)-(13) and (14)-(16) were combined in Eq. (10) to calculate the final nutrient availability score for each metric. Soil texture and exchangeable bases were not included here, as their empirical relationships with normalized productivity showed opposite trends compared to their implementation in the IIASA metric (Fig. 1 vs. Tables 2 and S9), likely due to indirect effects of soil moisture and related organic matter accumulation.

In contrast to the IIASA metric of constraints on nutrient availability, the adjusted metrics were significantly related with normalized productivity (Figs. 10 and 11), albeit with low $R^{2}$ values. The same analyses stratified by soil moisture (Tables S12 and S14) gave similar results for the intermediate fresh and fresh-moist moisture classes (i.e., those with the majority of data points), while stratification by soil type generally weakened relationships between the metrics and normalized productivity (only for Podzols and Regosols, could the metrics always describe variation; Tables S13 and S15). Only on a few occasions did the soil variables included in metric 1 show a (borderline) significant correlation with the residuals of the relationship between normalized productivity and the adjusted metrics (and the associated $R^{2}$ values were always low $(\leq 0.005)$; Table S16). We therefore conclude that $\mathrm{SOC}$, soil $\mathrm{C}: \mathrm{N}$, and $\mathrm{pH}$ are generally well implemented in this adjusted metric, at least for the database considered here. For adjusted metric 2, however, significant associations with higher $R^{2}$ values emerged, thus indicating suboptimal implementation of the variables in the metric, but the sign of the significant slope differed depending on whether normalization method 1 or 2 was used (Table S17).

Five nutrient availability gradients were selected to evaluate the performance of the adjusted metrics in the absence of confounding climate and $\mathrm{N}$ deposition effects (Fig. S2). Both metrics were capable of describing variation in productivity for all gradients, with $R^{2}$ values of $0.092-0.383$ (Tables 4 and 5). Variable implementation was generally good, except for SOC in adjusted metric 2 . There, SOC was significantly negatively associated with the residuals of the productivitymetric relationship (for four out of five gradients; Tables S18 and S19). Both the results of the national database and the gradients thus indicate that the adjusted metrics explain part of the spatial variation in productivity, and that adjusted metric 1 performs better than adjusted metric 2. Further adjustments, for example with other soil variables, may be needed to increase their performance.

\section{Discussion}

\subsection{Identifying potentially confounding factors}

Soil moisture varies between dry and very wet across Sweden and may obfuscate associations between nutrient-related 
Table 4. Evaluation of adjusted nutrient availability metric 1 for selected nutrient availability gradients in Sweden (Fig. S2). Statistics indicate the relationship between productivity (mean annual increment $-\mathrm{m}^{3} \mathrm{ha}^{-1} \mathrm{yr}^{-1}$ ) and the metric. For (near) significant variables (i.e., $P<0.10)$, parameter estimates \pm s.e.m. and the proportion of variation explained $\left(R^{2}\right)$ are given. For Norway spruce, no TEB gradient without substantial variation in climate was found, so that only for Scots pine was there a gradient in TEB. Abbreviations: TEB: total exchangeable bases. Error bars represent the s.e.m.

\begin{tabular}{llll}
\hline $\begin{array}{l}\text { Dominant tree } \\
\text { species }\end{array}$ & $\begin{array}{l}\text { Soil moisture } \\
\text { gradient }\end{array}$ & $\begin{array}{l}\text { TEB } \\
\text { gradient }\end{array}$ & $\begin{array}{l}\text { Productivity } \\
\text { gradient }\end{array}$ \\
\hline Norway spruce & slope $=1.6 \pm 0.4$ & n/a & $\begin{array}{l}\text { slope }=1.6 \pm 0.4 \\
P<0.01\end{array}$ \\
& $\begin{array}{l}P<0.01 \\
R^{2}=0.125\end{array}$ & & $R^{2}=0.150$ \\
& $n=132$ & & $n=78$ \\
\hline Scots pine & slope $=1.4 \pm 0.2$ & slope $=1.1 \pm 0.3$ & slope $=1.9 \pm 0.3$ \\
& $P<0.01$ & $P<0.01$ & $P<0.01$ \\
& $R^{2}=0.208$ & $R^{2}=0.205$ & $R^{2}=0.350$ \\
& $n=141$ & $n=59$ & $n=67$ \\
\hline
\end{tabular}

N/a: not applicable

soil properties and (normalized) productivity. Across our database, we indeed observed that certain soil properties (SOC, soil $\mathrm{C}: \mathrm{N}$ ratio, TEB) were related with soil moisture (Fig. S3), and also normalized productivity depended on soil wetness (Fig. 5): productivity was highest for intermediate soil moisture levels, and was significantly reduced for the most dry and wet soils. The influence of soil moisture on productivity can be explained as follows: at high water content, the anoxic rooting environment inhibits root and microbial respiration. Tree productivity is thus suppressed, both directly due to the lack of oxygen for the tree itself and because nutrient supply is limited due to the inhibition of mineralization (Gorham, 1991). For relatively dry soils, however, productivity is reduced because of water limitation (which has been shown to occur in southern Sweden - Bergh et al., 1999), lower nutrient inputs through groundwater, fewer periods with easily available nutrients in the soil solution (Qian and Schoenau, 2002), and lower retention (Larcher, 2003; Roy et al., 2006) and supply (Binkley and Hart, 1989) of nutrients by organic matter. In summary, any associations between a soil variable and productivity should be interpreted in view of the fact that soil moisture may act as a factor influencing both this soil variable and productivity. We therefore performed our analyses not only for the complete set of data but also for the data stratified by soil moisture to assess whether relationships between soil properties and productivity would change.

In the same way as for soil moisture, stratification by soil type might help in resolving nutrient-productivity relationships. Soil properties and productivity differed among the five most common soil types in the database (i.e., Histosols, Gleysols, Regosols, Leptosols, and Podzols - Fig. S4). To some extent, these differences among soil types overlapped with those observed for soil moisture classes (e.g., wet Histosols had the highest SOC, soil C: N, and the lowest produc- tivity), but additional patterns emerged as well (e.g., Podzols had a particularly low TEB stock). Although actual differences in nutrient availability among soil types will in part underlie the variations in productivity, other factors related to soil type (e.g., wetness, soil depth, or the rooting environment) may also influence productivity (Binkley and Hart, 1989). The main analyses of the current study were therefore stratified by both soil moisture and type to test the robustness of associations between nutrient-related soil properties and normalized productivity.

Many studies have shown the strong influence of $\mathrm{N}$ deposition on forest productivity (e.g., Laubhann et al., 2009; Solberg et al., 2009; de Vries et al., 2014; Binkley and Högberg, 2016; Wang et al., 2017). As expected, $\mathrm{N}$ deposition correlated to some extent with some of the soil variables considered in the present study, such as the total soil $\mathrm{N}$ stock and concentration (Fig. 4b). Furthermore, N deposition was strongly positively related to productivity. However, this effect of $\mathrm{N}$ deposition on productivity cannot be separated from the influence of climate and light, as all these factors increase together in the north-south direction. Nevertheless, we argue that for the goals of this study, i.e., investigating soil nutrient-productivity relationships across Sweden and developing a nutrient metric, the spatially varying $\mathrm{N}$ deposition is not problematic since the normalization for climate and species according to method 1 (Fig. 3a) at the same time also removed the influence of the confounding $\mathrm{N}$ deposition on productivity. Accordingly, residual productivity was generally not correlated with $\mathrm{N}$ deposition (Table S3). The response variable derived from method 2 (i.e., actual / attainable productivities for spruce - Fig. 3b), in contrast, correlated strongly with $\mathrm{N}$ deposition (Table S4) because both actual / attainable productivity and $\mathrm{N}$ deposition increased from north to south. Consequently, relationships 
between actual / attainable productivity and soil data for this method were unavoidably confounded by $\mathrm{N}$ deposition.

\subsection{Question 1 - normalized productivity vs. single and combined soil variables}

Soil C : N ratio had a negative effect on normalized productivity for both methods (Figs. 7b and 8b). Apart from high $\mathrm{N}$ concentrations at low $\mathrm{C}: \mathrm{N}$, increased productivities with decreasing $\mathrm{C}: \mathrm{N}$ ratio can follow from its influence on litter decomposition and mineralization, and thus on nutrient availability: when the ratio in organic matter is high, microbes more strongly immobilize $\mathrm{N}$ to adjust their internal $\mathrm{C}$ to $\mathrm{N}$ stoichiometry. As a consequence, $\mathrm{N}$ is not easily released and made available for plant uptake. A low $\mathrm{C}: \mathrm{N}$ ratio, however, facilitates $\mathrm{N}$ mineralization (Roy et al., 2006) and thus enhances $\mathrm{N}$ availability (Wilkinson et al., 1999).

The relationship of $\ln$ SOC with normalized productivity, which showed an optimum (Figs. 7a and 8a), is partly explained by the role of SOM in storing and exchanging nutrients, but also partly by the confounding effect of soil moisture. At high moisture levels, SOC most likely increases because decomposition is reduced in water-saturated soils, leading to organic matter accumulation (Fig. S3a). Anoxic soils impede productivity because of the aforementioned prevention of root respiration and reduced supply of newly available nutrients through mineralization. At low SOC, however, productivity supposedly decreases with decreasing SOC because of water limitation and low availability of organic matter, which acts as a nutrient store. Together, these results suggest that the empirical relationship between SOC and productivity might have an optimum below which soil fertility is reduced due to a lack of sufficient organic matter, and above which high SOC indicates hostile rooting conditions and limited nutrient supply through slow mineralization. The first aspect is thus included in the IIASA metric (Fig. 1), while the decreasing part of the curve should be included in the empirical relationship of SOC with nutrient availability if the effect of reduced decomposition is not captured by any of the other soil variables in an updated metric.

Soil factors other than the soil $\mathrm{C}: \mathrm{N}$ ratio and SOC either exhibited only a marginal influence on normalized productivity or their effect depended on the approach (Table 2). N stocks could explain variation across both methods, but their explanatory power was rather modest for method 1 . We anticipate that if we aim to develop metrics applicable beyond the boreal biome, including $\mathrm{N}$ stock will be of limited value, as this variable is only loosely related to $\mathrm{N}$ availability (Högberg et al., 2017).

Mineral soil clay fractions had a weak but significantly positive effect on normalized productivity. Even though clay particles can protect SOM from decomposition (Xu et al., 2016), clay soils in the Swedish database in all likelihood positively influence nutrient availability by means of their negative charges that serve as cation exchange sites (i.e., for
$\mathrm{NH}_{4}^{+}, \mathrm{K}^{+}, \mathrm{Ca}^{2+}$, and $\mathrm{Mg}^{2+}$ - IIASA and FAO, 2012). Effects of TEB and $\mathrm{pH}$ were dependent on the method, possibly reflecting differences between regional (method 1) and national (method 2) variation in nutrient availability.

All equations resulting from multiple regression analysis combining different soil variables contained the soil $\mathrm{C}: \mathrm{N}$ ratio and SOC (Table 3), confirming that, in the absence of direct soil nutrient data, these are key and complementary determinants of nutrient availability in northern coniferous forests. Qualitatively considered, associations of $\mathrm{C}: \mathrm{N}$ ratio $(-)$, SOC (concave quadratic after log transformation), $\mathrm{N}$ stock $(+)$, and clay fraction $(+)$ with normalized productivity were consistent for both approaches (Table 2). Together with their abilities to explain variation, the consistent effects of soil $\mathrm{C}: \mathrm{N}$ and SOC suggest these soil variables have the most potential for inclusion in an improved nutrient availability metric.

\subsection{Question 2 - evaluation of the IIASA metric}

Although the IIASA metric of constraints of nutrient availability was originally designed for arable lands, we opted to start with this metric for a few reasons. Apart from the fact that to our knowledge it represents the only attempt so far to develop a generic nutrient metric, the structures of its formulas (Eqs. 6-9) reflect general mechanisms that link soil properties to nutrient availability, which are also valid for nonagricultural ecosystems. Soil $\mathrm{pH}$ for example shows a typical optimum effect on nutrient availability, while SOC and TEB have a direct positive nonlinear influence (IIASA and FAO, 2012). The final weighing of the four partial scores (Eq. 10) finds its rationale in the idea that if a certain soil property is particularly suboptimal, it will be the most important nutrient-related determinant of productivity, with less influence of the other soil properties that are closer to or within their optimal range. This way of weighing can be considered a type of interaction, but one that cannot be implemented in a simple linear regression model. Hence, our main reason for adopting the IIASA metric as a starting point is that, in spite of its simplicity, it is based on theoretical considerations. Moreover, adopting this structure allows for updating with other datasets - something that can probably not be achieved with multiple regression equations (see Sect. 4.4).

The IIASA metric of constraints on nutrient availability does not clarify much variation in normalized productivity among Swedish forests. Moreover, SOC, soil texture, TEB, and $\mathrm{pH}_{\mathrm{w}}$ were apparently not optimally implemented. A low performance of the IIASA metric in its current form for the Swedish database was expected, as it was initially developed for evaluating (constraints on) the soil fertility of agricultural ecosystems, and the Swedish database contains variable values outside the ranges to which the metric is sensitive. Soil conditions of agroecosystems indeed greatly differ from the boreal forests investigated in the present study. Many Swedish forest soils are for instance coarse textured, 
Table 5. Evaluation of adjusted nutrient availability metric 2 for selected nutrient availability gradients in Sweden (Fig. S2). Statistics indicate the relationship between productivity (mean annual increment $-\mathrm{m}^{3} \mathrm{ha}^{-1} \mathrm{yr}^{-1}$ ) and the metric. For (near) significant variables (i.e. $P<0.10$ ), parameter estimates \pm s.e.m. and the proportion of variation explained $\left(R^{2}\right)$ are given. For Norway spruce, no TEB gradient without substantial variation in climate was found, so that only for Scots pine was there a gradient in TEB. Abbreviations: C: N: soil carbonto-nitrogen ratio; TEB: total exchangeable bases. Error bars represent the s.e.m.

\begin{tabular}{llll}
\hline $\begin{array}{l}\text { Dominant tree } \\
\text { species }\end{array}$ & $\begin{array}{l}\text { Soil moisture } \\
\text { gradient }\end{array}$ & TEB gradient & $\begin{array}{l}\text { Productivity } \\
\text { gradient }\end{array}$ \\
\hline Norway spruce & slope $=0.31 \pm 0.08$ & n/a & $\begin{array}{l}\text { slope }=0.36 \pm 0.08 \\
P<0.01\end{array}$ \\
& $P<0.01$ & & $R^{2}=0.188$ \\
& $R^{2}=0.092$ & & $n=78$ \\
& $n=132$ & & slope $=0.52 \pm 0.08$ \\
& slope $=0.28 \pm 0.05$ & slope $=0.23 \pm 0.06$ & $P<0.01$ \\
Scots pine & $P<0.01$ & $P<0.01$ & $R^{2}=0.383$ \\
& $R^{2}=0.177$ & $R^{2}=0.213$ & $n=67$ \\
\hline
\end{tabular}

N/a: not applicable

and in addition, the database contains wet-soil forests, while arable soils are typically not water saturated.

\subsection{Question 3-adjustments of the IIASA metric}

Based on results of the analyses for Question 1, the nutrient availability metric was adjusted by (i) including an empirical optimum in the influence of SOC on normalized productivity, and (ii) including soil $\mathrm{C}: \mathrm{N}$, thus more explicitly incorporating the availability of $\mathrm{N}$. In the current analysis, soil texture and TEB were excluded from the metrics, as they exhibited negative instead of the expected positive associations with normalized productivities (IIASA and FAO, 2012), probably due to indirect effects of low soil oxygen, reduced decomposition, and suppressed productivity where the proportion of sand is low and TEB is high.

In contrast to the original metric developed by IIASA, the adjusted metrics described some variation across all approaches using the full database (Figs. 10 and 11). Variables were generally properly implemented, at least for the adjusted metric 1 (Table S16). For metric 2, significant (but normalization-method-dependent) associations emerged between residuals of normalized productivity and SOC and $\mathrm{pH}$ (Table S17). The stratified analyses confirm that the metrics are an improvement, at least for those soil moisture classes and soil types with sufficient data points (Tables S12-15). Moreover, each metric could describe spatial variation in productivity for five manually selected local nutrient availability gradients (Tables 4 and 5). The coefficients of determination were generally higher for these gradients than for the database analyses, likely because the gradients did not require a normalization for climate (the latter increased the uncertainty on the response variable; see Sect. 4.5 on sources of uncertainty and future challenges). Lastly, the gradients generally confirmed the correct implementation of soil variables in adjusted metric 1 (Table $\mathrm{S} 18$ ), whereas for metric 2, scores for high SOC might be overestimated (Table S19).

Variation in normalized productivity explained by the adjusted metrics $\left(R^{2}=0.03-0.21\right.$ and $\left.R^{2}=0.06-0.18\right)$ was similar to the variation explained by multiple regression equations $\left(R^{2}=0.18-0.22\right)$ that contained the same (and more) soil variables as the metrics. The metrics, however, have the advantage that they can be updated more easily than equations from multiple regressions, especially if additional soil parameters need to be included for other ecosystems. Moreover, the interaction effect - with the highest weight for the least optimal soil parameter - cannot be mimicked with a multiple regression approach. In order to further adjust the metrics, and to test to what extent they can already describe variation in nutrient availability outside of Swedish conifer forests, additional datasets with productivity and soil information are needed. Such datasets include large-scale inventories such as the one considered in the present study, but also local gradients and nutrient manipulation experiments. The latter two have lower generalizability, but offer the advantage that normalization for climate is not needed.

\subsection{Sources of uncertainty and future challenges}

Even though normalized productivity was significantly related to soil properties, and to our adjusted metrics, much of the variation in normalized productivity remains unexplained. The considerable unexplained variation may have multiple reasons. Apart from a possible lack of soil and nutrient data more closely related to $\mathrm{N}$ availability than the ones available in our database, another possible factor reducing $R^{2}$ values could be the quality of the data in the database. This could for instance be due to an insufficient number of replicates sampled per data point ( $n=3$ for the soils), although this is probably of limited importance because of the 
large number of data points in the database itself. A more important source of uncertainty is probably the inevitable uncertainty related to the response variable, i.e., climatenormalized aboveground productivity. This includes uncertainty in the original productivity estimates (for example, for which differences in management or disturbances likely increased variability) and additional variation caused by soil moisture effects on oxygen availability (which we accounted for by also performing analyses on split datasets). However, there is also uncertainty related to the normalization for climate: by taking residuals of the productivity vs. climate regression model (method 1), we for instance unintentionally removed not only the direct effect of climate on productivity but also its indirect effect through nutrient availability. Normalized productivity based on this method thus mainly represents productivity as influenced by regional variation in nutrient availability. The approach taking actual / attainable productivity as a response variable (method 2) does not suffer from this issue, but there the estimates of attainable productivity come with a high uncertainty, as they were based on only limited experimental data to establish a relationship between productivity and intercepted radiation. As a consequence, the low $R^{2}$ values are partly due to shortcomings of the normalization procedure that can only be overcome by using datasets in which climate does not vary but nutrient availability does. Such datasets are provided by local gradients, such as the five local nutrient availability gradients that we selected from our database for additional evaluation of our adjusted metrics.

The similar and significant results for the different methods (1 and 2) and subsets of the database (regions, soil moisture classes, and soil types) indicate that the findings about the soil properties and nutrients are generally robust. The adjusted metrics explained up to $21 \%$ of the variation in normalized productivity. It is unclear to what degree the influence of nutrient availability is covered by this percentage. Future studies, in which additional soil data (e.g., P) can be included, will need to verify this. In any case, the significant relationships with normalized productivity, the better implementation of the soil variables, and the capability of the metrics to explain up to $38 \%$ of the variation in productivity across different gradients imply a significant improvement compared to the original IIASA metric for this database.

A key challenge in the further development of a metric describing spatial variation in nutrient availability both within and outside the boreal biome is differential nutrient limitation. Eventually, we want to be able to compare for example $\mathrm{N}$-limited and P-limited systems. The original structure of the IIASA metric, which was kept in our adjusted metrics, facilitates this by allowing the inclusion of multiple soil variables such as soil $\mathrm{C}: \mathrm{N}$ (mainly relating to $\mathrm{N}$ availability), $\mathrm{pH}$ (among others a critical factor controlling $\mathrm{P}$ availability), and TEB in one single metric. In fact, the IIASA metric is particularly useful in this regard, as it gives more weight to the soil factor with the lowest score. This corresponds to reality and enables accounting for the type of nutrient limitation. For instance, if soil $\mathrm{C}: \mathrm{N}$ is high, indicating $\mathrm{N}$ limitation, the metric score will be substantially reduced by this high $\mathrm{C}: \mathrm{N}$, while at low $\mathrm{C}: \mathrm{N}$ other limiting factors can dominate the metric score.

\section{Conclusions}

In our database, the soil properties explaining most variation in tree productivity across Swedish conifer forests were $\mathrm{SOC}$ and the soil $\mathrm{C}: \mathrm{N}$ ratio. The empirical relationship between SOC and normalized productivity showed an optimum, reflecting the soil characteristic's direct positive effect on nutrient availability only at low soil carbon concentrations, whereas at high SOC, its effect was masked by other environmental factors (soil moisture and oxygen, and temperature), affecting both SOC and productivity through their role in regulating organic matter formation and decomposition rates. The soil $\mathrm{C}: \mathrm{N}$ ratio showed the expected negative correlation with normalized productivity in the present database. Based on the resulting regression equations, we adjusted the IIASA metric for Swedish conifer forests by modifying the relationship between SOC and nutrient availability, and by incorporating soil $\mathrm{C}: \mathrm{N}$.

The current nutrient availability metrics were developed based on data from Swedish conifer forests only, and can therefore not be extrapolated outside the boreal biome. In order to verify if development of a metric that compares the nutrient status across sites also beyond the boreal biome is feasible, the adjusted metrics developed in this study will need to be validated (and if necessary further modified) based on other forests elsewhere for which the necessary soil information is available. In a later stage, this approach can then be expanded to other ecosystem types.

Code and data availability. The Swedish national database and $\mathrm{R}$ scripts with statistical analyses are available at https://www.dropbox.com/s/llbz1p6rtkrccjh/KevinVanSundert_ etal_Biogeosciences_2018.7z?dl=0 (Van Sundert et al., 2018).

Supplement. The supplement related to this article is available online at: https://doi.org/10.5194/bg-15-3475-2018-supplement.

Author contributions. SV and KVS conceived the study. KVS performed the analyses and wrote the paper. JAH provided statistical advice and JS provided data. All authors contributed to the discussions and the writing of the paper.

Competing interests. The authors declare that they have no conflict of interest. 
Acknowledgements. This research was supported by the Fund for Scientific Research - Flanders (FWO aspirant grant to KVS; FWO postdoctoral fellowship to SV) and by the European Research Council grant ERC-SyG-610028 IMBALANCE-P. We also acknowledge support from the ClimMani COST Action (ES1308). The Swedish Forest Soil Inventory is part of the national environmental monitoring commissioned by the Swedish Environmental Protection Agency. EC-JRC-MARS provided precipitation data. We thank Ivan Janssens for his valuable comments on earlier versions of the paper. Published with support from the Belgian University Foundation.

Edited by: Edzo Veldkamp

Reviewed by: three anonymous referees

\section{References}

Bergh, J., Linder, S., Lundmark, T., and Elfving, B.: The effect of water and nutrient availability on the productivity of Norway spruce in northern and southern Sweden, Forest Ecol. Manag., 119, 51-62, https://doi.org/10.1016/S03781127(98)00509-X, 1999.

Bergh, J., Linder, S., and Bergstrom, J.: Potential production of Norway spruce in Sweden, Forest Ecol. Manag., 204, 1-10, https://doi.org/10.1016/j.foreco.2004.07.075, 2005.

Binkley, D. and Hart, S. C.: The components of nitrogen availability assessments in forest soils, Adv. Soil S., 10, 57-112, 1989.

Binkley, D. and Högberg, P.: Tamm review: revisiting the influence of nitrogen deposition on Swedish forests, Forest Ecol. Manag., 368, 222-239, https://doi.org/10.1016/j.foreco.2016.02.035, 2016.

Bol, R., Julich, D., Brödlin, D., Siemens, J., Kaiser, K., Dippold, M.A., Spielvogel, S., Zilla, T., Mewes, D., von Blanckenburg, F., Puhlmann, H., Holzmann, S., Weiler, M., Amelung, W., Lang, F., Kuzyakov, Y., Feger, K-H., Gottselig, N., Klumpp, E., Missong, A., Winkelmann, C., Uhlig, D., Sohrt, J., von Wilpert, K., Wu, B., and Hagedorn, F.: Dissolved and colloidal phosphorus fluxes in forest ecosystems - an almost blind spot in ecosystem research, J. Plant Nutr. Soil Sc., 179, 425-438, 2016.

Chapin, F. S., Matson, P. A., and Mooney, H. A.: Principles of Terrestrial Ecosystem Ecology, Springer-Verlag, New York, USA, 2002.

Chapman, H. D.: Cation exchange capacity, in: Methods of Soil Analysis Part 2: Chemical and Microbiological Properties, 2nd Edn., edited by: Pace, A. L., Miller, R. H., and Keeney, D. R., American Society of Agronomy and Soil Science Society of America, Madison, Wisconsin, USA, 891-901, 1982.

Cleveland, C. C., Townsend, A. R., Taylor, P., Alvarez-Clare, S., Bustamante, M. M. C., Chuyong, G., Dobrowski, S. Z., Grierson, P., Harms, K. E., Houlton, B. Z., Marklein, A., Parton, W., Porder, S., Reed, S. C., Sierra, C. A., Silver, W. L., Tanner, E. V. J., and Wieder, W. R.: Relationships among net primary productivity, nutrients and climate in tropical rain forest: a pan-tropical analysis, Ecol. Lett., 14, 939-947, https://doi.org/10.1111/j.1461-0248.2011.01658.x, 2011.

de Vries, W., Du, E., and Butterbach-Bahl, K.: Short and longterm impacts of nitrogen deposition on carbon sequestration by forest ecosystems, Curr. Opin. Env. Sust., 9/10, 90-104, https://doi.org/10.1016/j.cosust.2014.09.001, 2014.

Dieleman, W. I. J., Vicca, S., Dijkstra, F. A., Hagedorn, F., Hovenden, M. J., Larsen, K. S., Morgan, J. A., Volder, A., Beier, C., Dukes, J. S., King, J., Leuzinger, S., Linder, S., Luo, Y., Oren, R., De Angelis, P., Tingey, D., Hoosbeek, M. R., and Janssens, I. A.: Simple additive effects are rare: a quantitative review of plant biomass and soil process responses to combined manipulations of $\mathrm{CO}_{2}$ and temperature, Glob. Change Biol., 18, 2681-2693, https://doi.org/10.1111/j.1365-2486.2012.02745.x, 2012.

ESRI: ArcGIS Desktop: release 10, Environmental Systems Research Institute, Redlands, California, USA, 2011.

Fernández-Martínez, M., Vicca, S., Janssens, I. A., Sardans, J., Luyssaert, S., Campioli, M., Chapin, F. S., Ciais, P., Malhi, Y., Obersteiner, M., Papale, D., Piao, S. L., Reichstein, M., Roda, F., and Penuelas, J.: Nutrient availability as the key regulator of global forest carbon balance, Nature Climate Change, 4, 471476, https://doi.org/10.1038/NCLIMATE2177, 2014.

Fraser, L. H., Pither, J., Jentsch, A., Sternberg, M., Zobel, M., Askarizadeh, D., Bartha, S., Beierkuhnlein, C., Bennett, J.A., Bittel, A., Boldgiv, B., Boldrini, I. I., Bork, E., Brown, L., Cabido, M., Cahill, J., Carlyle, C. N., Campetella, G., Chelli, S., Cohen, O., Csergo, A. M., Díaz, S., Enrico, L., Ensing, D., Fidelis, A., Fridley, J. D., Foster, B., Garris, H., Goheen, J. R., Henry, H. A. L., Hohn, M., Jouri, M. H., Klironomos, J., Koorem, K., Lawrence-Lodge, R., Long, R., Manning, P., Mitchell, R., Moora, M., Müller, S. C., Nabinger, C., Naseri, K., Overbeck, G. E., Palmer, T. M., Parsons, S., Pesek, M., Pillar, V. D., Pringle, R. M., Roccaforte, K., Schmidt, A., Shang, Z., Stahlmann, R., Stotz, G. C., Sugiyama, S., Szentes, S., Thompson, D., Tungalang, R., Undrakhbold, S., van Rooyen, M., Wellstein, C., Wilson, J. B., and Zupo, T.: Worldwide evidence of a unimodal relationship between productivity and plant species richness, Science, 349, 302-305, https://doi.org/10.1126/science.aab3916, 2015.

Friedrich, U., von Oheimb, G., Kriebitzsch, W. U., Schlesselmann, K., Weber, M. S., and Hardtle, W.: Nitrogen deposition increases susceptibility to drought - experimental evidence with the perennial grass Molinia caerulea (L.) Moench, Plant Soil, 353, 59-71, https://doi.org/10.1007/s11104-011-1008-3, 2012.

Goll, D. S., Brovkin, V., Parida, B. R., Reick, C. H., Kattge, J., Reich, P. B., van Bodegom, P. M., and Niinemets, U.: Nutrient limitation reduces land carbon uptake in simulations with a model of combined carbon, nitrogen and phosphorus cycling, Biogeosciences, 9, 3547-3569, https://doi.org/10.5194/bg-9-35472012, 2012.

Gorham, E.: Northern peatlands - role in the carbon cycle and probable responses to climatic warming, Ecol. Appl., 1, 182-195, https://doi.org/10.2307/1941811, 1991.

Grand, S. and Lavkulich, L. M.: Short-range order mineral phases control the distribution of important macronutrients in coarsetextured forest soils of coastal British Columbia, Canada, Plant Soil, 390, 77-93, https://doi.org/10.1007/s11104-014-2372-6, 2015.

Hägglund, B. and Lundmark, J. E.: Site index estimation by means of site properties, Studia forestalia Suecica 138, Technical Report, Swedish University of Agricultural Sciences, Stockholm, Sweden, 1977.

Högberg, P., Näsholm, T., Franklin, O., and Högberg, M. N.: Tamm review: on the nature of the nitrogen limitation to plant growth 
in Fennoscandian boreal forests, Forest Ecol. Manag., 403, 161185, https://doi.org/10.1016/j.foreco.2017.04.045, 2017.

Holford, I. C. R.: Soil phosphorus: its measurement, and its uptake by plants, Soil Res., 35, 227-240, 1997.

Hyvönen, R., Persson, T., Andersson, S., Olsson, B., Agren, G. I., and Linder, S.: Impact of long-term nitrogen addition on carbon stocks in trees and soils in northern Europe, Biogeochemistry, 89, 121-137, https://doi.org/10.1007/s10533-007-9121-3, 2008.

IIASA and FAO: Global Agro-ecological Zones (GAEZ v3.0), International Institute for Applied Systems Analysis, Laxenburg, Austria and Food and Agricultural Organization of the United Nations, Rome, Italy, 2012.

Janssens, I. A., Dieleman, W., Luyssaert, S., Subke, J. A., Reichstein, M., Ceulemans, R., Ciais, P., Dolman, A. J., Grace, J., Matteucci, G., Papale, D., Piao, S. L., Schulze, E. D., Tang, J., and Law, B. E.: Reduction of forest soil respiration in response to nitrogen deposition, Nat. Geosci., 3, 315-322, https://doi.org/10.1038/ngeo844, 2010.

Larcher, W. (Ed.): Physiological Plant Ecology, Springer-Verlag, Berlin, Germany, 2003.

Laubhann, D., Sterba, H., Reinds, G. J., and de Vries, W.: The impact of atmospheric deposition and climate on forest growth in European monitoring plots: an individual tree growth model, Forest Ecol. Manag., 258, 1751-1761, https://doi.org/10.1016/j.foreco.2008.09.050, 2009.

Lundin, L.: MarkInfo, available at: http://www-markinfo.slu.se/ eng/index.html, last access: 23 March 2017, 2011.

Maindonald, J. H. and Braun, W. J.: DAAG: data analysis and graphics data and functions, available at: http://CRAN.R-project. org/package $=$ DAAG (last access: 7 June 2018), 2015.

Minderma, G.: Addition decomposition and accumulation of organic matter in forests, J. Ecol., 56, 355-362, 1968.

Neyroud, J.-A. and Lischer, P.: Do different methods used to estimate soil phosphorus availability across Europe give comparable results?, J. Plant Nutr. Soil Sc., 166, 422-431, 2003.

Nilsson, T. and Lundin, L.: Uppskatning av volymvikten i svenska skogsjordar från halten organiskt kol och markdjup, Prediction of bulk density in Swedish forest soils from the organic carbon content and soil depth, Department of Forest Soils, Swedish University of Agricultural Science, Uppsala, Sweden, 2006.

Nohrstedt, H. O.: Response of coniferous ecosystems on mineral soils to nutrient additions: a review of Swedish experiences, Scand. J. Forest Res., 16, 555-573, https://doi.org/10.1080/02827580152699385, 2001.

Norby, R. J., Warren, J. M., Iversen, C. M., Medlyn, B. E., and McMurtrie, R. E.: $\mathrm{CO}_{2}$ enhancement of forest productivity constrained by limited nitrogen availability, P. Natl. Acad. Sci. USA, 107, 19368-19373, https://doi.org/10.1073/pnas.1006463107, 2010.

Novotny, R., Burianek, V., Sramek, V., Hunova, I., Skorepova, I., Zapletal, M., and Lomsky, B.: Nitrogen deposition and its impact on forest ecosystems in the Czech Republic - change in soil chemistry and ground vegetation, Iforest, 10, 48-54, 2015.

Odin, H., Eriksson, B., and Perttu, K.: Temperaturklimatkartor för svenskt skogsbruk, Temperature climate maps for Swedish forestry, Department of Forest Soils, Swedish University of Agricultural Science, Uppsala, Sweden, 1983.

Olsson, M.: Soil Survey in Sweden, European Soil Bureau, Ispra, Italy, 1999.
Olsson, M. T., Erlandsson, M., Lundin, L., Nilsson, T., Nillson, A., and Stendahl, J.: Organic carbon stocks in Swedish podzol soils in relation to soil hydrology and other site characteristics, Silva Fenn., 43, 209-222, https://doi.org/10.14214/sf.207, 2009.

Qian, P. and Schoenau, J. J.: Practical applications of ion exchange resins in agricultural and environmental soil research, Can. J. Soil Sci., 82, 9-21, 2002.

R Core Team: R: a language and environment for statistical computing, R Foundation for Statistical Computing, Vienna, Austria, available at: https://www.R-project.org/ (7 June 2018), 2015.

Roy, R. N., Finck, A., Blair, G. J., and Tandon, H. L. S.: Plant nutrition for food security - A guide for integrated nutrient management, FAO, Rome, Italy, 2006.

Soil Survey Staff (Eds.): Keys to soil taxonomy, 12th Edn., USDA-National Resources Conservation Service, Washington DC, USA, 2014

Solberg, S., Dobbertin, M., Reinds, G. J., Lange, H., Andreassen, K., Garcia Fernandez, P., Hildingsson, A., and de Vries, W.: Analyses of the impact of changes in atmospheric deposition and climate on forest growth in European monitoring plots: a stand growth approach, Forest Ecol. Manag., 258, 1735-1750, https://doi.org/10.1016/j.foreco.2008.09.05,2009.

Stendahl, J., Johansson, M. B., Eriksson, E., Nilsson, A., and Langvall, O.: Soil organic carbon in Swedish spruce and pine forests - differences in stock levels and regional patterns, Silva Fenn., 44, 5-21, https://doi.org/10.14214/sf.159, 2010.

Swedish Meteorological and Hydrological Institute.: 2015 års totaldeposition av Ammonium Kväve $\left(\mathrm{mg} \mathrm{N} / \mathrm{m}^{2}\right)$, available at: http://www.smhi.se/sgn0102/miljoovervakning/kartvisare.php? lager=15DTOT_NHX__ last access: 7 June 2018.

Swedish Meteorological and Hydrological Institute.: 2015 års totaldeposition av Oxiderat Kväve $\left(\mathrm{mg} \mathrm{N} / \mathrm{m}^{2}\right)$, available at: http://www.smhi.se/sgn0102/miljoovervakning/kartvisare.php? lager=15DTOT_NOY_ _ last access: 7 June 2018.

Terrer, C., Vicca, S., Hungate, B. A., Philips, R. P., and Prentice, I. C.: Mycorrhizal association as a primary control of the $\mathrm{CO}_{2}$ fertilization effect, Science, 353, 72-74, https://doi.org/10.1126/science.aaf4610, 2016.

Thomas, R. Q., Brookshire, E. N. J., and Gerber, S.: Nitrogen limitation on land: how can it occur in Earth system models?, Glob. Change Biol., 21, 1777-1793, https://doi.org/10.1111/gcb.12813, 2015.

Vadeboncoeur, M. A.: Meta-analysis of fertilization experiments indicates multiple limiting nutrients in northeastern deciduous forests, Can. J. Forest Res., 40, 1766-1780, https://doi.org/10.1139/X10-127, 2010.

Van Sundert, K., Horemans, J. A., Stendahl, J., and Vicca, S.: Data and statistics supporting "The influence of soil properties and nutrients on conifer forest growth in Sweden, and the first steps in developing a nutrient availability metric", available at: https://www.dropbox.com/s/llbz1p6rtkrccjh/ KevinVanSundert_etal_Biogeosciences_2018.7z?dl=0, last access: 7 June 2018

Venables, W. N. and Ripley, B. D. (Eds.): Modern applied statistics with S, 4th Edn., Springer, New York, USA, 2002.

Vicca, S., Luyssaert, S., Penuelas, J., Campioli, M., Chapin, F. S., Ciais, P., Heinemeyer, A., Högberg, P., Kutsch, W. L., Law, B. E., Malhi, Y., Papale, D., Piao, S. L., Reichstein, M., Schulze, E. D., and Janssens, I. A.: Fertile forests produce biomass more effi- 
ciently, Ecol. Lett., 15, 520-526, https://doi.org/10.1111/j.14610248.2012.01775.x, 2012.

von Liebig, J.: Die organische Chemie in ihrer Anwendung auf Agrikultur und Physiologie, Friedrich Vieweg Sohn, Braunschweig, Germany, 1840.

Wang, R., Goll, D., Balkanski, Y., Hauglustaine, D., Boucher, O., Ciais, P., Janssens, I. A., Penuelas, J., Guenet, B., Sardans, J., Bopp, L., Vuichard, N., Zhou, F., Li, B., Piao, S., Peng, S., Huang, Y., and Tao, S.: Global forest carbon uptake due to nitrogen and phosphorus deposition from 1850 to 2100 , Glob. Change Biol., 23, 4854-4872, https://doi.org/10.1111/gcb.13766, 2017.

Wieder, W. R., Cleveland, C. C., Smith, W. K., and Todd-Brown, K.: Future productivity and carbon storage limited by terrestrial nutrient availability, Nat. Geosci., 8, 441-444, 2015.
Wilkinson, S. R., Grunes, D. L., and Sumner, M. E.: Nutrient interactions in soil and plant nutrition, in: Handbook of Soil Science, edited by: Sumner, M. E., Taylor and Francis, Leiden, the Netherlands, 89-112, 1999.

Wood, S. N.: Generalized additive models: an introduction with R, Chapman and Hall/CRC, Leiden, the Netherlands, 2006.

Xu, X., Shi, Z., Li, D. J., Rey, A., Ruan, H. H., Craine, J. M., Liang, J. Y., Zhou, J. Z., and Luo, Y. Q.: Soil properties control decomposition of soil organic carbon: results from data-assimilation analysis, Geoderma, 262, 235-242, https://doi.org/10.1016/j.geoderma.2015.08.038, 2016. 